\title{
The Long ANd The Short Of Emerging MARKet DebT
}

\author{
Luis Opazo, Claudio Raddatz, and Sergio L. Schmukler *
}

August 2009

\begin{abstract}
Emerging economies have tried to promote long-term debt since it reduces maturity mismatches and the probability of crises. This paper uses unique evidence from the leading case of Chile to study to what extent there is domestic demand for long-term instruments. We analyze monthly asset-level portfolios of Chilean institutional investors (mutual funds, pension funds, and insurance companies) and compare their maturity structure to that of US bond mutual funds. Despite being thought to invest long term, Chilean asset-management institutions (mutual and pension funds) hold large amounts of short-term assets relative to US mutual funds and Chilean insurance companies. Shorttermism is not driven by lack of instrument availability or tactical behavior. Instead, it seems to be explained by the desire to minimize inflation risk and, more importantly, by manager incentives that tilt demand toward short-term instruments. Extending the maturity of emerging market debt may require reducing risk and reshaping investor incentives.
\end{abstract}

JEL Classification Codes: F36, G11, G20, O16

Keywords: debt maturity, maturity structure, asset management, institutional investors, portfolio allocation, pension funds, mutual funds, insurance companies

\footnotetext{
* We are grateful to Matias Braun, Augusto de la Torre, Randall Dodd, and participants at conferences organized by the IMF and the World Bank (Washington, DC), the NIPFP-DEA Workshop (Delhi, India), the Superintendency of Pensions and Universidad Adolfo Ibáñez (Santiago, Chile) for their very useful comments. We are indebted to the Chilean Superintendency of Pensions (in particular to Solange Berstein, Pablo Castañeda, and Eduardo Fajnzylber) and the Superintendency of Insurance and Securities (in particular to Marco Morales) for giving us unique data that made this paper possible. We are also grateful to Alfonso Astudillo Blanche, Leandro Brufman, Maria Mercedes Politi, Fernando Sepulveda, and Camilo Vio for excellent research assistance, and to Prof. Juan Antonio Cuesta-Albertos for generously sharing his code for the functional data version of the Kolmogorov-Smirnov test. Opazo is with the Central Bank of Chile. Raddatz and Schmukler are with the World Bank, Development Economics Research Group. Email addresses: lopazo@bcentral.cl, craddatz@worldbank.org, and sschmukler@worldbank.org. The views expressed here do not necessarily represent those of the Central Bank of Chile or the World Bank.
} 


\section{Introduction}

The behavior of investors and the maturity structure of their investments continue to receive much attention. This interest experienced a boost with the emerging market crises of the 1990s, but the need to understand how investors invest, what incentives they face, and how financial institutions and capital markets operate has become even more relevant as financial crises engulf developing and developed countries alike (Rajan, 2005; and Calomiris, 2008).

Having access to long-term financing allows governments and firms to finance large investments over time, reducing rollover risk and the potential for crises. ${ }^{1}$ In fact, several well-known financial crises have been linked to maturity mismatches. ${ }^{2}$ This is especially true in emerging economies, which often face a significant degree of shorttermism. As a consequence, many developing countries have actively tried to develop markets for long-term lending through various measures that tackle different parts of the financial system, such as promoting institutional investors, lengthening the maturity structure of sovereign debt, indexing financial instruments, and pursuing macroeconomic stabilization.

Given the benefits of long-term debt and the efforts to encourage it, what then explains short-term borrowing in emerging economies? To what extent can maturities be lengthened? Different explanations for this short-term maturity structure have emerged. Traditional arguments focus on the incentives of emerging country borrowers to issue short-term debt to signal to markets their commitment to sound policies and economic

\footnotetext{
${ }^{1}$ See, for instance, Barro (1997), Eichengreen and Hausman (1999), Tirole (2003), Borensztein et al. (2005), Alfaro and Kanczuk (2006, 2009), and Borensztein et al. (2006).

${ }^{2}$ See, for example, Radelet and Sachs (1998), Chang and Velasco (1999), The Economist (1999), and Buiter and Siber (2008).
} 
management and to avoid moral hazard (Calvo, 1988; Blanchard and Missale, 1994; Rodrik and Velasco, 2000; and Jeanne, 2009). But recent explanations place more emphasis on the role of investor behavior and incentives. In particular, investor risk aversion might prompt countries to borrow short term (Broner et al., 2007). By lending long term, investors incur the price risk of long-term bonds since they might need to sell those bonds before they mature. Therefore, the risk premium charged on long-term debt induces the demand side to borrow short term. A related investor-side explanation for the prevalence of short-term contracts is based on the incentives driven by market discipline (Shleifer and Vishny, 1990; Bebchuk and Stole, 1993; Stein, 2005; Bolton et al., 2006; and Jin and Kogan, 2008). When investors can discipline fund managers by withdrawing money following poor performance, as in the case of open-end funds, managers may be unable to take advantage of long-term arbitrage opportunities that take time to pay off.

Despite the recent emphasis on the role of investor behavior and incentives as determinants of portfolio choice regarding debt maturity, little evidence exists on how emerging market investors actually structure the maturity of their portfolios, and thus demand instruments with different investment horizons. This lack of evidence is mainly due to the difficulty in obtaining data on investor portfolios. ${ }^{3}$

This paper sheds new light on the demand for long-term assets and the determinants of this demand by analyzing unique and rich data on actual portfolios of a large set of institutional investors and examining a benchmark emerging market case, where conditions were set to foster long-term investments. In particular, we construct the maturity structures of several types of Chilean domestic institutional investors (medium-

\footnotetext{
${ }^{3}$ A separate literature studies the maturity structure at the firm level. See, for example, Claessens et al. (2000), Bleakley and Cowan (2005, 2008), and Schmukler and Vesperoni (2006).
} 
and long-term bond mutual funds, pension funds, and insurance companies) based on detailed asset-level time-series holdings between 1996 and 2005. We focus most of the analysis on Chilean asset-management institutions (mutual and pension funds). We compare their maturity structure to each other, to that of US mutual funds (a developed country benchmark), and to that of Chilean insurance companies (an asset-liability management benchmark).

The empirical approach followed in this paper has important advantages for understanding how much emerging market investors demand long-term instruments, and what factors affect their maturity structure decisions. First, the comparison across different types of institutional investors is particularly insightful since it is difficult to identify on theoretical grounds the optimal maturity structure for a given investor; it depends on factors such as the investor's goals, preferences, and the markets in which it participates (Campbell and Viceira, 2002). Comparing the maturity structure of different investors allows us to have benchmarks and test whether one type of investor is significantly more tilted toward the short term. It also allows us to control for specific sources of variation in the maturity structure across investors and asset classes. In particular, the comparison between institutional investors in Chile and the US sheds light on how much further emerging economies might be able to extend the maturity of their fixed-income assets by promoting the growth of domestic institutional investors. The Chilean institutional investors we analyze are relatively developed and sophisticated, managing professionally a large pool of assets. So they should be able to take on risk and invest long term. In addition, the within-country comparison across investor types helps us shed additional light on the role that different factors play in shaping the maturity 
structure of portfolios, since it allows us to compare the behavior of investors that operate in the same environment and face the same set of instruments.

The second advantage of the present analysis is that Chile is an ideal benchmark case among emerging markets. It has a relatively developed capital market with many types of large institutional investors and the government has made a conscious effort to provide an adequate institutional and macroeconomic framework and to extend the maturity structure of investments. A series of government reforms targeted both the supply and demand side of funds and are probably unparalleled regarding the potential impact on long-term capital markets. ${ }^{4}$ As a result, Chile is probably one of the emerging economies where the ability of investors to invest long term is the greatest. Moreover, by working with Chile we are able to use unique data on detailed portfolio holdings of bank deposits, sovereign bonds, and corporate bonds of mutual funds, pension funds, and insurance companies at high frequencies (monthly, and also daily for pension funds).

The main findings of the paper can be summarized as follows. Asset-management institutions in Chile (both mutual funds and pension funds) hold a large amount of shortterm instruments (bank deposits including cash, government paper, and corporate debt) that can eventually be easily liquidated. For example, over the entire sample period, domestic mutual funds hold $38 \%$ of their assets up to one year, $59 \%$ up to three years, and $73 \%$ up to five years, with an average maturity of 3.88 years. Similarly, pension funds hold $34 \%$ of their (non-equity) assets up to one year, $60 \%$ up to three years, and

\footnotetext{
${ }^{4}$ On the supply side, Chile was a pioneer in the development of institutional investors and has established relatively early a broad institutional investor base. For further details, see Raddatz and Schmukler (2008). On the demand side, Chile has introduced reforms to foster capital market development, with corporations and the government issuing a wide range of securities. The central bank has also significantly extended the maximum maturity of local currency bonds issued. Moreover, Chile's stable macroeconomic performance since the early 1990s and its long history of issuing inflation-linked instruments have also reduced the risk of long-term assets and have made placements less costly.
} 
$79 \%$ up to five years, with an average maturity of 3.16 years. Relative to the US, the maturity structures of Chilean mutual funds and pension funds are substantially and significantly shorter. For example, while mutual funds and pension funds in Chile hold approximately $60 \%$ of their portfolio in assets with a maturity of up to three years, US multi-sector mutual funds (which hold a range of government and corporate paper) hold $24 \%$ of their portfolios in assets with a maturity of up to three years and have an average maturity that reaches 9.55 years.

After documenting that Chilean asset managers have significantly shorter maturity structures than their US counterparts, we explore the potential causes of this short-termism. In particular, we study the role of supply constraints, tactical behavior, risk management, and incentives in accounting for the documented maturity differences between Chile and the US.

We find that Chilean short-termism is not determined by the supply of instruments or tactical behavior. For instance, pension funds do not exhaust the supply of long-term instruments and demand well below the total issuance of government bonds at different maturities. Moreover, although maturities beyond 20 years are uncommon in Chile, the maturity differences between Chilean and US asset managers are such that, after dropping those long-term assets from the data, the maturity structures of Chilean mutual and pension funds only approach that of US short-term mutual funds. Regarding tactical behavior, daily data suggest that pension funds do not seem to accumulate cash and other short-term investments in anticipation of future buying opportunities, such as the relaxation of regulations or crises that depress asset prices. 
The risk profile of different investment instruments and agency factors that tilt manager incentives seem to play an important role in explaining the short-termism observed. Regarding the risk profile, mutual and pension funds are significantly more long-term oriented when holding inflation-indexed assets that are less risky at longer maturities than nominal Chilean peso assets. This suggests that these investors try to avoid inflation risk, which is especially important for long-term nominal instruments. However, the risk profile seems to be just a part of the explanation. Chilean institutional investors are more short term than US investors even when investing in US dollar denominated instruments or in developed country assets. Furthermore, the maturity structure of Chilean mutual funds investing in other emerging economies is more shortterm than that of US mutual funds investing in the same type of countries. The maturity structures of Chilean and US investors tend to become similar only when comparing the holdings of inflation-protected government instruments by Chilean mutual funds to that of US dollar denominated instruments by US mutual funds. This suggests that Chilean mutual funds need substantial risk reduction to extend their maturities. In the case of Chilean pension funds, they are systematically shorter than US mutual funds regardless of the asset class.

The important role of incentives in the short-termism of Chilean asset managers come from at least two sources: the underlying investors and the liability structure. Relative to US mutual funds, Chilean mutual funds are subject to more redemptions from underlying investors. Therefore, their short-termism can be partly accounted for by a higher outflow risk. Furthermore, managers of Chilean mutual funds that invest abroad (targeted to more sophisticated underlying investors) also invest more long term than 
those that invest domestically, suggesting that when faced with investors that tend to seek higher returns, Chilean fund managers have incentives to invest at longer horizons. An important final piece of evidence regarding the importance of incentives is that the maturity structure of Chilean insurance companies (which face the same supply of domestic assets) is substantially more tilted toward the long term, with an average maturity of 10.32 years. The main difference between insurance companies and mutual and pension funds is that the former have long-term liabilities since investors are promised a defined benefit (de la Torre et al., 2007). Therefore, insurance companies benefit from matching the maturity structure of their assets and liabilities. Mutual and pension funds, on the other hand, are pure asset managers and seem to have incentives to invest short term, regardless of the investment horizons of their underlying investors. The evidence from insurance companies reinforces the conclusion that the maturity structure of asset managers is not driven by the supply side of instruments, but by the decision of asset managers to invest short term.

The rest of the paper is organized as follows. Section 2 describes the data. Section 3 characterizes the maturity structure of Chilean and US institutional investors. Section 4 analyzes the factors that might determine the maturity composition of institutional investors. Section 5 concludes and highlights some policy implications.

\section{Data}

The main data used in this study consist of asset-level holdings of institutional investors and come from different sources. The data on Chilean mutual funds and insurance companies come from the Superintendency of Securities and Insurance 
(Superintendencia de Valores y Seguros, SVS). The data on Chilean pension funds, the most comprehensive data, come from the Superintendency of Pensions (Superintendencia de Pensiones, SP). The data on US mutual funds come from Morningstar. Additional data come from the Central Bank of Chile (Banco Central de Chile) and other sources described in the paper. See Appendix Table 1 for a summary of the main data used.

The data on Chilean mutual funds contain detailed portfolios of all existing medium- and long-term funds at a monthly frequency during the period September 2002 to December $2005 .{ }^{5}$ The database comprises 447,664 observations; 436,393 for domestic funds and 11,271 for foreign funds (those investing outside of Chile). ${ }^{6}$ It includes information on the type of security, currency denomination, price, units held, and maturity date.

For pension funds, we use a panel of their portfolio investments in fixed-term assets for each of the existing funds during the period 1996-2005 at monthly and daily frequencies. We use panel data with the amount of deposits (including cash as deposits with a one-day maturity), corporate bonds, and government bonds held by fund per unit of time. ${ }^{7}$ At a monthly frequency, there are a total of 7,501,210 observations, representing the portfolio holdings of the funds. The dataset contains information on the holdings of 104,789 different securities for 57 funds between July 1996 and December 2005. In addition to this monthly dataset, we use in other exercises a different dataset with daily portfolios of the universe of funds and pension fund administrators (henceforth PFAs) in

\footnotetext{
${ }^{5}$ Chilean mutual funds are classified according to the type and investment horizon of their assets. Fixedincome funds include money management funds (with horizons of 90 or 365 days) and medium- and longterm funds. We only use the latter, since the former would be tilted toward the short term by construction.

${ }^{6} \mathrm{We}$ consider a fund to be foreign if its median investment abroad as a percentage of the total portfolio is $50 \%$ or higher. Otherwise, it is considered to be domestic. We obtained similar results when relaxing the criteria to $40 \%$ and $30 \%$.

${ }^{7}$ By law, since September 2002, each pension fund administrator (PFA) offers five funds with different risk profiles, subject to different portfolio regulations.
} 
operation, which contains 201,288,833 observations for 62 funds between July 1996 and July $2008 .^{8}$ The daily data have the same fields included in the monthly database.

The data on Chilean insurance companies comprise monthly portfolio holdings from June 2002 to December 2005. The database contains 2,156,576 observations corresponding to the fixed-term assets of 36 insurance companies. Information on security type, maturity date, and currency, among others, are available in this dataset.

The data on the maturity structure of US bond mutual funds come from Morningstar. The available data consist of the fraction of the total portfolio invested at different maturities (up to three years, between three and five years, five and seven years, seven and ten years, ten and 15 years, 15 and 20 years, 20 and 30 years, and above 30 years). We use the universe of 186 US bond mutual funds (multi-sector, short-term, and emerging market mutual funds) operating between 2003 and 2005. Due to limited data availability we use annual data with a total of 11,440 data points. ${ }^{9}$

\section{Maturity Structure}

We describe the demand for long-term assets by concentrating first on the maturity structure of Chilean mutual funds. Figure 1 plots the fraction of investments in fixed-term assets per year-to-maturity, both within each maturity range and accumulated. The figure is built by determining at each point in time (each month) the term to maturity

\footnotetext{
${ }^{8}$ The difference between the number of funds in the monthly and daily datasets is due to the extended period the daily dataset covers.

${ }^{9}$ We use Morningstar's categories to group US bond mutual funds (short-term, multi-sector, and emerging market funds). Short-term bond mutual funds invest in a variety of bonds, from the most creditworthy, such as government bonds, to mortgage and corporate bonds (they may invest in more speculative high-yield and emerging market debt on rare occasions). Multi-sector bond mutual funds are usually more diversified than other types of bond mutual funds, investing in a wide range of foreign and domestic government and corporate bonds. Emerging market mutual funds invest more than $65 \%$ of their portfolios in bonds from developing countries. Data are available for 125 short-term mutual funds, 42 multi-sector mutual funds, and 19 emerging market mutual funds.
} 
of each instrument in a mutual fund portfolio, measuring the fraction of the value of all assets invested at different terms to maturity, and then averaging these fractions across mutual funds and time. Let $d_{i, t}$ and $w_{i, t}{ }^{k}$ denote the term to maturity of asset $i$ at time $t$, and the share of fixed-term assets invested in asset $i$ at time $t$ by fund $k$, respectively. The fraction of fund $k$ 's fixed-term assets with term to maturity $D$ is

$$
W_{D, k, t}=\sum_{i} w_{i, t}^{k} I\left(d_{i, t}=D\right),
$$

where $I$ denotes an indicator function that takes on the value one if the condition is met. The average fraction of fund $k$ 's fixed-term assets invested at maturity $D$ across time is, therefore,

$$
W_{D, k}=\frac{1}{T_{k}} \sum_{t=1}^{T_{k}} W_{D, k, t},
$$

where $T_{k}$ is the number of periods in which mutual fund $k$ is active. Finally, the overall average fraction of fixed-term assets invested at maturity $D$ across mutual funds and months corresponds to

$$
W_{D}=\frac{1}{N} \sum_{k=1}^{N} \frac{T_{k}}{T} W_{D, k}
$$

where $T$ denotes the number of months included in the entire sample period, and $N$ is the number of active mutual funds. The fractions computed correspond to the empirical probability distribution function (PDF) of the term to maturity of a Chilean peso invested by mutual funds in fixed-term assets. The empirical cumulative distribution function (CDF) of the term to maturity can easily be obtained by adding these fractions up to a given maturity. Finally, in addition to the average CDF, Figure 1 also reports the $25^{\text {th }}$ and $75^{\text {th }}$ percentiles of the CDF across mutual funds. 
Figure 1 shows that Chilean domestic mutual funds are heavily invested in shortterm assets. For example, they invest $38 \%$ of their portfolio up to one year, $59 \%$ up to three years, and $73 \%$ up to five years. Moreover, they hold almost all of their securities in assets maturing within 15 years (95\%). However, the distributions vary greatly across mutual funds, as shown by the $25^{\text {th }}$ and $75^{\text {th }}$ inter-quartile range across funds, averaged over time: the fraction of the fixed-term portfolio invested up to one year varies between $24 \%$ and $50 \%$. Panel B shows that portfolio weights decline exponentially; the highest density is observed at short maturities, after which probabilities systematically decline.

Next, we look at the maturity structure of Chilean pension funds. While mutual funds are open-ended investment vehicles subject to redemptions and the investment horizon of their underlying investors is unknown, one might expect pension funds to have longer investment horizons. In particular, we study pension funds at their "accumulation phase," when young pensioners contribute to the funds' growth and outweigh old, retiring pensioners. Therefore, pension funds are receiving constant net inflows and do not need to hold liquid assets to meet cash withdrawals. ${ }^{10}$ Furthermore, pension fund investors are saving for retirement, so their investment horizon should be at least as long as that of mutual fund investors, and probably much longer.

Figure 2 shows the maturity structure of Chilean pension funds for the entire sample period 1996-2005 and for the multi-fund period 2002-2005. In both periods PFAs are heavily invested in short-term assets. For example, for the entire (multi-fund) period, they invest $24 \%$ (34\%) up to one year, $45 \%$ (60\%) up to three years, and 74\% (79\%) up to five years. Moreover, they hold almost all of their securities in assets maturing within ten years (98\% and $96 \%$ for the entire and multi-fund periods, respectively). The

\footnotetext{
${ }^{10}$ See the evidence in Section 4.D.
} 
distributions do not vary much by PFA as shown by the $25^{\text {th }}$ and $75^{\text {th }}$ inter-quartile range calculated across PFAs and averaged over time. The fraction of the fixed-term portfolio invested up to one year varies only between $21 \%$ and $28 \%$ during the entire sample period and between $32 \%$ and $37 \%$ during the multi-fund period. Even smaller degrees of dispersion are observed at other ranges of the CDFs. Panels A2 and B2 show that the portfolio weights decline exponentially, similarly to the case of mutual funds although presenting a higher degree of volatility.

Figure 3 compares Chilean mutual and pension funds. ${ }^{11}$ The distributions of both types of institutional investors differ at very short and very long maturities, but otherwise are very similar. For example, Panel $\mathrm{C}$ shows that both pension and mutual funds hold around $60 \%$ of their fixed-term assets at a maturity of up to three years, and above that maturity pension funds are slightly more short-term investors relative to mutual funds: pension funds hold $79 \%$ of their assets up to five years and $88 \%$ up to seven years, while mutual funds hold $73 \%$ and $80 \%$ up to that maturity, respectively. These small differences are not statistically significant. As shown in Columns (ii) to (viii), for most of the reported maturity cuts, standard t-tests cannot reject the hypotheses that the average fraction of assets held by pension funds and mutual funds are equal. As a result, the average maturities of assets held by pension funds (3.16 years) and mutual funds ( 3.88 years) are not very different (even in statistical terms), as shown in Panel D Column (i). However, because of the differences observed at maturities shorter than six months and longer than 15 years (Columns ii and vii), a two-sample goodness-of-fit test for

\footnotetext{
${ }^{11}$ We compare mutual and pension funds during the multi-fund period (September 2002 to December 2005). Although pension fund data are available for a longer time period, the rest of the paper (with the exception of Figure 7) uses pension fund data for only the multi-fund period to have a comparable sample period across all investor types.
} 
functional-data (henceforth KS test) rejects the hypothesis that the observed maturity structures of pension funds and mutual funds are generated by the same underlying distribution (Column ix). ${ }^{12}$ In fact, in unreported results, when we compare the maturity structures at monthly frequency with a coarser distribution (as the one used in Figure 4), the hypothesis that the maturity structures of these two types of investors are generated by the same distribution cannot be rejected at conventional levels.

Although the maturity structures of Chilean mutual and pension funds look short term, it is necessary to compare them to that of other institutional investors that can serve as benchmarks. To do so, we analyze the maturity structure of US fixed-income mutual funds. US funds provide a good benchmark of how funds operating in a developed capital market (with a different set of investment opportunities) behave. To compare Chilean mutual and pension funds to US mutual funds, we present the maturity structures grouped within eight large bins, determined by the availability of US mutual fund data from Morningstar.

Figure 4 shows that Chilean mutual and pension fund holdings are much more tilted toward the short term than US mutual funds. Notably, this is even the case when

\footnotetext{
${ }^{12}$ This test was proposed by Cuesta-Albertos et al. (2006), and consists on applying a standard two-sample Kolmogorov-Smirnov (KS) test to the random projections of each set of functional data; in our case the samples of maturity structures of all pension funds and mutual funds, respectively. We start by forming two groups of vectors of length $M$ corresponding to the time-average maturity structures of all individual pension and mutual funds $W_{D, k}=(1 / T) \sum_{t} W_{D, k, t}$, discretized by month, with $M$ corresponding to the longest maturity observed (in months). Each of these vectors is projected on a random direction $h \in \mathbb{R}^{M}$, obtaining two samples of random projections (one for each type of investor) of sizes $n_{1}$ and $n_{2}$, the number of pension funds and mutual funds respectively. The standard two-sample Kolmogorov-Smirnov test is then applied to these samples. The process is repeated $M$ times using different random directions, and the resulting set of p-values is adjusted for false discovery rate under dependency as in Benjamini and Yekuteli (2001). The p-value reported in the table corresponds to the minimum of the adjusted p-values, which indicates the level of confidence with which at least one of the $M$ hypotheses can be rejected. An alternative statistic proposed by Cuesta-Albertos et al. (2007), based on the fraction of rejections among the $M$ hypotheses, yields similar conclusions (not reported).
} 
comparing pension funds to US short-term mutual funds. For example, while pension funds hold $60 \%$ of their fixed-term instruments in assets with a maturity of up to three years, US multi-sector and short-term mutual funds hold, respectively, $24 \%$ and $48 \%$ of their portfolio in assets with that maturity. The differences persist throughout the distribution. For example, Chilean pension funds hold $79 \%$ in assets up to five years, while US mutual and short-term funds hold only $37 \%$ and $64 \%$, respectively, at that horizon. While Chilean pension funds do not hold assets with a term to maturity above 15 years, both US multi-sector and short-term mutual funds hold, respectively, $22 \%$ and $20 \%$ of their portfolio in assets with a term to maturity above 15 years, with some instruments surpassing a maturity of 30 years. All these differences result in a much longer average maturity for US multi-sector and short-term mutual funds (9.55 and 7.76 years, respectively) than for Chilean pension funds and mutual funds (3.16 and 3.88 years, respectively).

The distributions in Figure 4 are statistically different at all conventional significance levels. Standard t-tests reported in Columns (i) to (vii) of Panels D show that, at almost all maturity cuts and in terms of average maturities, Chilean pension and mutual funds are shorter than both US multi-sector and short-term mutual funds at a $1 \%$ significance level. Consistently, the KS tests show that the hypothesis that the two distributions compared in each panel are identical can easily be rejected. 


\section{What Drives the Maturity Structure?}

Here we analyze potential factors that may contribute to the short-termism shown in the previous section and we study to what extent they might play a role in determining the maturity structure of asset managers. By relying on different types of useful evidence, we focus on four factors: (a) instrument availability, (b) rebalancing (tactical behavior), (c) risk of investment instruments, and (d) managerial incentives.

\section{A. Instrument Availability}

It is possible that mutual and pension funds purchase short-term instruments because long-term ones are not available. As several papers argue, emerging market governments tend to borrow short term. ${ }^{13}$ Therefore, since most of their holdings are in domestic bonds, mutual and pension funds' fixed-term investments could simply be constrained by the availability of long-term instruments due to borrower decisions.

Although borrower decisions likely depend on the demand for different maturities and what we observe is an equilibrium outcome, our goal here is to explore whether, given the amounts of securities of different maturities available in equilibrium, any type of institutional investor is exhausting the supply of long-term instruments. For data availability reasons we focus on pension funds, but since the market for each type of bond has to clear, from these data we can infer the maximum amount of outstanding bonds at different maturities that could be held by other institutional investors.

Figure 5 shows the total amount of bonds issued by the government at different maturities between 1998 and 2008 and the fraction of those issuances purchased by

\footnotetext{
${ }^{13}$ See the discussion in the Introduction, and the references therein.
} 
pension funds. ${ }^{14}$ The figure contains separate panels per currency: nominal Chilean peso, indexed (inflation-linked) Chilean peso, and US dollar. The figure shows that in all cases pension funds purchase significantly less than the total amounts issued. On average, pension funds purchase $3 \%$ of issuances in Chilean pesos, $40 \%$ of government issuances in inflation-indexed pesos, and $15 \%$ of issuances in US dollars. Also, within each denomination, the fraction of long-term issuances purchased by pension funds is not much larger than that of short-term issuances. Even when looking at inflation-indexed bonds, the share of bonds with maturities above 10 years purchased by pension funds is only $41 \%$ (compared to $39 \%$ for indexed bonds with less than 10 years of maturity). This observation is relevant because government bonds are considered safe investments. In other words, even when riskless long-term assets are available, pension funds forgive those investment opportunities.

Regarding corporate debt, there is no information on the amount of issuances purchased by PFAs. However, we have data on the amount of corporate debt held by PFAs as a proportion of the outstanding corporate debt and their average maturities. Table 1 shows that PFAs hold on average $40 \%$ of outstanding corporate debt, declining from $58 \%$ in 1997 to $28 \%$ in 2004 . PFA's holdings are tilted toward issues with shorter maturities. While the average maturity of the outstanding debt is about 13 years, the average maturity of the debt held by PFAs is only five years. ${ }^{15}$ Again, this type of

\footnotetext{
${ }^{14}$ The Central Bank of Chile reports the information aggregating PFAs and insurance companies due to historical reasons. However, the incidence of insurance companies on these figures is negligible because they correspond to direct purchases, and insurance companies buy almost all of their government securities through intermediaries (banks). In contrast, pension funds bid directly for central bank paper. That is why we interpret these purchases as driven by PFAs.

${ }^{15}$ While there is no information on the amount of corporate debt issuances purchased by PFAs, we use data on the corporate debt holdings of PFAs as a proportion of the outstanding corporate debt (from Braun and Briones, 2008) and information on the average maturities of PFA corporate debt holdings compared to the
} 
information suggests that PFAs have not been constrained to expand their holdings of long-term bonds. ${ }^{16}$

Although PFAs and other Chilean institutional investors could extend the maturity of their holdings in domestic bonds, instrument availability can mechanically explain part of the differences observed with the US because the longest maturity available in Chile is shorter than that available in the US. While 30-year debt instruments are common in the US, instruments of this maturity have been uncommon in Chile during our sample period. Nevertheless, the documented differences in maturity structure between Chilean and US institutional investors are too large to be fully explained by the availability of instruments at the long end of the maturity structure. Even if we remove all investments beyond 20 years from the portfolios of US mutual funds and re-calculate the maturity structure up to 20 years only, US multi-sector mutual funds are still longer than Chilean funds. This exercise could account for at most $60 \%$ of the difference in average maturity between Chilean and US funds, leaving Chilean PFAs and mutual funds with a similar maturity structure to US short-term mutual funds (Figure 6).

\section{B. Rebalancing}

Institutional investors might hold a large fraction of short-term assets for tactical purposes to respond opportunistically to shocks, rebalancing their portfolios and taking advantage of good buying opportunities. This is known as "cash-in-the-market" pricing, and refers to the idea that holding liquidity is costly because less liquid assets have higher

average maturity of outstanding corporate debt (from the Chilean Superintendency of Pensions and the Superintendency of Securities and Insurance).

${ }^{16}$ With respect to the banking system, the proportion of certificate deposits held by PFAs has been very stable, oscillating between $25 \%$ and $30 \%$. But banking sector information is less relevant to assess the extent to which PFAs might be constrained by instrument availability because banks can accept any amount of deposits. 
expected returns, but agents may hold liquidity because on occasion they are able to make a profit by buying assets at fire-sale prices (Allen and Gale, 1994, 1998; and Allen and Carletti, 2008).

To study the rebalancing effects of short-termism, we conduct event studies with unique data from the Superintendency of Pensions on daily asset holdings of pension funds. We use two types of events relevant to pension fund managers: (a) the relaxation of regulatory constraints and (b) the occurrence of crisis periods. We focus on pension funds because we do not have high frequency (daily) portfolio data for other Chilean institutional investors. However, as we show below, pension funds experience significantly less outflows than mutual funds and, therefore, should be especially able to use their liquidity to take advantage of market opportunities in turbulent times instead of meeting redemptions. Furthermore, there were many regulatory changes related to pension funds that constitute interesting events to analyze.

Relaxation of Regulatory Constraints. The current legislation limits the amount of foreign assets held by PFAs. This threshold has been expanded from $16 \%$ to $45 \%$ of total assets through six amendments since 2002, increasing 4\% on March 1, 2002 and 5\% in each of the remaining cases. ${ }^{17}$ Data on portfolio composition indicate that these limits have been binding most of the time for Chilean PFAs (Raddatz and Schmukler, 2008), a fact that is consistent with the historical lobbying efforts of PFAs in favor of increasing these limits. Since these regulatory changes have typically been announced in advance, PFAs could accumulate liquidity prior to the deregulation to take advantage of such changes. In other words, if PFAs hold liquidity to take advantage of investment

\footnotetext{
${ }^{17}$ The remaining dates are May 29, 2003, March 1, 2004, August 9, 2007, December 18, 2007, and April 24, 2008.
} 
opportunities we should expect an increase in short-term holdings before the limits change and a reduction after their implementation.

Figure 7 (Panel A) shows the share of very short-term assets (those with maturity under 30 days) held by PFAs during the 40 days before and after the regulatory change. The share corresponds to the average across PFAs and is computed as a proportion of each PFA's total fixed-term assets. The figure shows that around the regulatory events the portfolio share of short-term assets does not change significantly. Moreover, shortterm holdings before a regulatory change are lower than the average holdings after the change. Concretely, the average share of short-term assets is $4.7 \%$ during the 40 days prior to a change in the limit and 5.4\% during the 40 days after the modification of the limit, registering a peak of $5.9 \%$ around the $30^{\text {th }}$ day after the change in the limit. Therefore, this evidence does not support the hypothesis that PFAs modify their shortterm asset holdings due to rebalancing purposes. We also analyzed (in unreported exercises) the response of PFAs to other regulatory events that change their investment opportunities, such as the release of information on the portfolios of competitors, finding no evidence of liquidity hoarding before those releases.

Crisis Periods. Several papers have proposed that crisis periods in emerging markets are frequently related to lack of liquidity, when assets are sold at fire-sale prices (Krugman, 1998; and Aguiar and Gopinath, 2005). To analyze changes in the short-term portfolio during crises, we study the evolution of short-term assets held by Chilean pension funds during the Asian and Russian crises.

Figure 7 (Panel B) shows the evolution of short-term assets during the crisis period of July 1997 to December 1998, indicating the dates of some of the main events 
occurring in international financial markets. The pattern of short-term asset holdings shows an increase from an average of $2 \%$ one week before the event to more than $3 \%$ two weeks after the Asian crisis hit South Korea in November 1997 (with the downgrade of Korean debt) and remains high for the rest of this turbulent period. If anything, the evolution of short-term assets is more consistent with a flight-to-liquidity strategy than with the hoarding of liquidity to take advantage of fire-sale asset prices. Results for the evolution of short-term assets around the September 11, 2001 terrorist attack yield similar conclusions (not reported).

In sum, the evidence in this section is inconsistent with pension funds holding liquid assets to act opportunistically and purchase securities at fire-sale prices. Short-term positions do not seem to respond to the events analyzed here.

\section{C. Risk of Investment Instruments}

Standard models of asset allocation indicate that the portfolio composition of an investor depends on the risk-return combination of the different assets available for investment (Campbell et al., 2001; and Campbell and Viceira, 2002). Thus, in principle, the shorter maturity structure of Chilean asset managers relative to US mutual funds could result from differences in the risk profiles of the assets in which they invest. In what follows, we explore several potential sources of these differences.

A first potential explanation related to risk is that the presence of higher inflation risk in Chile than in the US could tilt the portfolios of Chilean investors toward shorter maturities. Inflation movements are more difficult to predict in the long term, adding extra risk to the price of bonds with longer maturities. In other words, the comparisons presented above could be misleading since they aggregate all fixed-term instruments held 
by Chilean mutual and pension funds, including those in different currencies. For sure, US mutual funds do not hold instruments denominated in Chilean pesos, so the finding that they are more long term than Chilean mutual and pension funds could be driven by the lower inflation risk of their investments. To address this issue and shed light on how risk might be affecting managerial decisions, we report the maturity structure of portfolio holdings by currency. Namely, we consider holdings in nominal pesos, "hard currencies" (US dollar, euro, British pound, and yen), and indexed pesos (inflation-linked).

Figure 8 shows the maturity structure of Chilean mutual funds and pension funds by currency. In the case of mutual funds, the maturity structure of holdings in pesos is similar to that in hard currencies (with holdings in pesos slightly longer), while the maturity structure of holdings in inflation-linked pesos is significantly longer. In the case of pension funds, the maturity structure differs significantly across currencies. Pension funds are very short-term investors in pesos, less so in hard currencies, and even less so in inflation-linked instruments. For example, 56\% (76\%) of peso holdings are held in instruments maturing in less than one (three) year(s). On the contrary, less than $50 \%$ of hard-currency assets and about 30\% of inflation-linked ones are in assets maturing in less than one year. The differences in the distributions are statistically significant, as shown by the KS tests displayed in Panel E.

The patterns illustrated in Figure 8 are consistent with pension and mutual funds being more tilted toward the short term in assets with higher long-term risk. The price of nominal peso instruments responds to inflation volatility, which tends to increase with the maturity of the bond, thus the short-term structure. ${ }^{18}$ Hard currency bonds expose Chilean

\footnotetext{
${ }^{18}$ Although PFAs are asset managers and, therefore, have no liabilities to hedge against, for regulatory reasons they send monthly reports of their real returns to future pensioners and must base their publicity on
} 
investors to currency and inflation risks. Therefore, investors would be more willing to go long in hard currencies than in Chilean pesos (i.e., holding hard currencies allows investors to hedge part of the inflation risk) only if these risks commove strongly negatively in the long run, which does not seem to be the case of Chile. ${ }^{19}$ Not being exposed to currency or inflation risk, indexed peso bonds are relatively less risky than peso and hard-currency bonds, especially at longer maturities, which could account for the willingness of Chilean investors to buy more long-term indexed peso instruments. Therefore, for some types of instruments, asset managers might perceive a tradeoff between maturity, on the one hand, and currency and inflation risks, on the other hand. When they can reduce those risks, they seem more willing to invest more long term. This confirms the importance of comparing pension and mutual fund portfolios using instruments with different currency denominations. ${ }^{20}$

Figure 9 compares the holdings of Chilean mutual and pension funds in hard currencies and indexed pesos to those of US multi-sector mutual funds. The figure shows that, even when investing in these two types of instruments, Chilean investors still tend to

real returns. Thus, the reduction in real returns resulting from inflation can potentially affect their ability to capture new affiliates or generate outflows. Although there is not much evidence that the number of affiliates changes with returns, the ranking of PFAs by returns (typically used in publicities) seems to be positively correlated with the number of affiliates across PFAs (Cerda, 2005).

${ }^{19}$ While the correlation between monthly inflation and depreciations of the Chilean peso against the US dollar between 1990 and 2008 is about 0.17 , the correlations between annual and bi-annual inflation and depreciations are 0.35 and 0.49 , respectively.

${ }^{20}$ As mentioned above, portfolio allocation not only depends on the risk of different assets, but on their risk-return profile. The discussion of this section abstracts from return differentials and focuses only on risk differentials at different maturities. Establishing the optimal portfolio allocation from the historical returns of various assets requires data on the yield of a meaningful number of comparable maturity bins for instruments in pesos, hard currencies, and indexed pesos. This is beyond the scope of this paper. However, a simple calculation based on Central Bank of Chile data on the yields of four overlapping maturity bins for each currency class indicates that a mean-variance investor with a one-month horizon and subject to a noshort-sale constraint would invest only in indexed peso instruments. This evidence is available upon request. 
be more tilted toward the short term than US mutual funds. ${ }^{21}$ Average maturities of Chilean pension and mutual funds, for indexed pesos and hard currencies, are shorter and statistically different than that of US mutual funds (Panels C and D). For example, the average maturity in hard currency is 3.37 and 1.6 years for mutual and pension funds, respectively, while the one for US mutual funds is 9.55 years. There are some similarities with the maturity structure of US multi-sector mutual funds only when considering Chilean mutual fund portfolios in indexed pesos. In this case, the average share of assets with maturities of less than three and ten years held by Chilean mutual funds is similar to that held by US multi-sector funds (tests cannot be rejected at the 5\% significance level). Moreover, when comparing the maturity structure after censoring investments in assets with maturities beyond 20 years (which are rare in Chile, as explained above), the difference between Chilean mutual funds that invest in inflation-linked instruments and US mutual funds is no longer statistically significant, even against one-sided alternatives (not reported). Therefore, the evidence suggests that Chilean investors have a maturity profile that is similar to that of US multi-sector funds only when investing in those domestic securities with the lowest possible risk, such as government-backed instruments without inflation risk. ${ }^{22}$

\footnotetext{
${ }^{21}$ Additional estimates show that pension funds appear even more short term than US short-term mutual funds (not reported).

${ }^{22}$ Part of the difference in the maturity structure of Chilean PFAs relative to that of US mutual funds could result from the fact that Chilean PFAs hold an important part of their portfolio in variable-income assets, while by definition US fixed-term mutual funds do not. However, this does not seem to be the case. First, anecdotal evidence suggests that funds investing in various asset classes delegate the asset selection process to various independent asset-class managers (these are the so-called "multi-manager funds") and Chilean PFAs are no exception. Second, the maturity structure of bond pension funds (funds "E") is also shorter than that of US multi-sector mutual funds (not reported). Therefore, the evidence does not indicate that the differences in maturity structure between Chilean pension funds and US mutual funds are driven by differences in the set of instruments in which these funds invest.
} 
The finding that when investing in indexed pesos Chilean mutual funds behave similarly to US multi-sector mutual funds could indicate that the overall differences in maturity structure result solely from differences in the risk profile of the set of assets faced by institutional investors in emerging and developed countries. But additional evidence suggests that this is not the case.

First, available evidence from other emerging markets suggests that, if anything, investors in emerging markets should tilt their portfolios toward the long term relative to investors in developed countries. Broner et al. (2007) compute Sharpe ratios of short- and long-term bonds in various emerging markets and show that, on average, the difference in the Sharpe ratio of long- and short-term bonds is higher in emerging markets than in developed countries.

Second, we take advantage of the fact that both the Chilean and US mutual fund industries offer funds that only invest in emerging economies. This allows us to control for the assets available for investment and then compare how these different types of investors choose their portfolios. Figure 10 (Panel A) shows that Chilean mutual funds dedicated to emerging markets are more short term than US emerging market funds. The differences are significant. The average maturity of Chilean emerging market funds is 3.80 years in contrast to the 12.64 average maturity of US emerging market funds. Moreover, Chilean emerging market mutual funds invest $52 \%$ of their portfolio up to three years, $78 \%$ up to five years, and $99 \%$ up to ten years, whereas US emerging market mutual funds invest only $11 \%$ up to three years, $20 \%$ up to five years, and $54 \%$ up to ten years. In addition, Figure 10 (Panel B) shows that Chilean mutual funds that invest in 
developed countries are more short term (with an average maturity of 3.77 years) than US multi-sector funds (with an average maturity of 9.55 years). ${ }^{23}$

Taken as a whole, the evidence from this section suggests that the risk profile of the available investment opportunities affects the degree of short-termism of mutual and pension funds. Institutional investors in Chile are sensitive to the risks involved in investing in different instruments and emerging market assets are riskier than those from developed markets. However, the evidence shows that only when investing in government-backed securities with no inflation risk the maturity structure of some Chilean institutional investors (medium-to-long term mutual funds) becomes similar to that of their US counterparts. In all other cases, the evidence suggests that institutional investors in Chile seem to be too tilted toward the short term relative to US institutional investors, even when facing similar sets of available assets.

\section{D. Managerial Incentives}

Traditional theories of asset allocation focus on the problem of an isolated investor whose goal is to maximize wealth or consumption at some point in time. Recent papers have started to study the consequences that conflicts of interest between fund managers and underlying investors, and the incentive schemes that may arise as a result, have for manager risk-taking behavior (Sharfstein and Stein, 1990; Chevalier and Ellison, 1999; Kapur and Timmermann, 2005; and Stein, 2005). There at least two factors that can affect manager incentives and that are analyzed here: the behavior of underlying investors and the liability structure.

\footnotetext{
${ }^{23}$ We do not report statistical tests for these differences because we have just two dedicated Chilean mutual funds that only invest in developed countries.
} 
The underlying investors can play an important role in how managers allocate the maturity structure of their portfolio partly through the redemptions or outflows they generate. ${ }^{24}$ Outflows are costly to managers because they force them to liquidate assets, reducing at the same time the pool of assets they administer and their associated fees (Rajan, 2005). These outflows can be the result of underlying investors trying to align manager incentives (through market discipline) or simply because of liquidity needs. Market discipline might lead to short-termism because risk averse mutual and pension fund managers have incentives to obtain returns that are (at least) similar at a high frequency to those of their competitors, which make them averse to engaging in investments that are profitable in the long run (like holding long-term bonds) but can have poor short-term performance or high risk (Shleifer and Vishny, 1990; and Stein, 2005). ${ }^{25}$ Regardless of their origin, more outflows would generate incentives for managers to hold more short-term investments that are easy to liquidate.

To analyze how significant outflows (negative inflows) are and whether they might be driving the results, we compute the outflow that each mutual fund faces each month. We calculate the net inflows to a fund $k$ at time $t, I_{t}^{k}$, as the change in the fund value $W_{t}^{k}$ during a month, adjusted by the gross return of the portfolio in that month $R_{t}^{k}$ :

\footnotetext{
${ }^{24}$ Since mutual funds are open-ended investment vehicles, investors decide at each point in time how much funds they invest, and they may decide to withdraw their investments at any moment. In the case of pension funds, pensioners must contribute to the pension fund system, but they are able to select any PFA (and any fund within the PFA itself). Namely, pensioners can switch among funds, both across and within administrators, but they have to stay within the system.

${ }^{25}$ Since short-term assets tend to be less volatile, they allow managers to be within the industry and cope with market discipline. Moving to more long-term investments can have rewards, but they come at a risk: their upside potential for returns is accompanied by a higher downside risk. If the risks are greater than the extra returns, it would be difficult to deviate from an equilibrium in which all managers hold short-term returns. On the other hand, an equilibrium in which all managers are tilted toward long-term investments is not sustainable to the extent that investors monitor manager behavior on a short-term basis (Stein, 2005). Holding long-term assets is more likely to make returns more volatile and generate more outflows.
} 


$$
I_{t}^{k}=W_{t}^{k}-W_{t-1}^{k}\left(1+R_{t}^{k}\right)
$$

We use this method to calculate net inflows for both Chilean and US mutual funds. In the case of pension funds, we compute this measure by aggregating daily data on net inflows into each fund directly collected by the Chilean Superintendency of Pensions. ${ }^{26}$

The results are displayed in Figure 11. Panel A shows the cumulative distribution of net inflows $I_{t}^{k}$ relative to fixed-income assets for Chilean mutual funds and PFAs and US mutual funds. Negative (positive) values are outflows (inflows). The figure shows that Chilean mutual funds face significant outflows, much more than US mutual funds. For example, the historical probability of experiencing a net outflow of $3 \%$ of the portfolio or more is $9 \%$ in the case of US multi-sector mutual funds and $33 \%$ in the case of Chilean mutual funds. Therefore, the short-termism of Chilean mutual funds relative to US mutual funds might be partly explained by the larger outflows they face. To complement this evidence, Panel B shows the fraction of fixed-term assets held in shortterm assets (up to one and three months) and the probability of outflows of that magnitude. ${ }^{27}$ Chilean mutual funds hold $9.3 \%$ of their fixed-term assets in instruments with maturity of less than one month, and the probability of an outflow of that magnitude occurring is almost $22 \%$. The estimated figures for US multi-sector bond funds are $3.7 \%$ and $6.6 \%$ respectively. Thus, according to this estimation, the liquid assets held by Chilean mutual funds would be covering a much more likely outflow than those held by US funds. Therefore, their short-termism might be explained by redemption risk.

\footnotetext{
${ }^{26}$ Though not reported, we also computed the monthly inflows using the values and returns derived from our monthly database and obtained qualitatively similar results.

${ }^{27}$ The values reported correspond to the probability that would be required to have a value at risk (VAR) equal to the fraction of fixed-term assets held by funds at maturities of up to 30 and 90 days. For US funds, we do not have information on the maturity structure at less than three years, so we use the extreme assumption that within the zero to thee year interval, the maturity structure of US funds is proportional to that of Chilean mutual funds.
} 
The short-termism of Chilean pension funds, however, cannot be explained by outflows. The distribution of net inflows of Chilean PFAs is significantly tilted to the right, indicating that they are not subject to large outflows. For example, a $1 \%$ net outflow has a historical probability of $3 \%$ for PFAs and $38 \%$ for mutual funds. Though they face very different outflows, the short-term positions of mutual funds and pension funds are not very different, as shown in Figure $3 .{ }^{28}$ The estimations reported in Figure 11, Panel B, also show that pension funds seem to hold a large fraction of liquid assets for low-probability events: they hold $4.4 \%$ of their fixed-term assets in instruments with a maturity of less than one month, while the probability of an outflow of that magnitude is negligible. To the extent that there is an opportunity cost of holding short-term instruments, pension funds are paying a high price for their elevated self-insurance levels.

The short-termism of pension funds might be explained by regulatory incentives trying to protect underlying investors rather than by the behavior of underlying investors. Pension funds are required to yield returns within established margins. In fact, pension fund managers are penalized by regulations when they deviate from industry standards, having to cover these losses with their own capital. This regulatory discipline might also help explain the argument that Chilean pension fund managers follow a tracking-error model of investment, which constrains them to be close to the average pension fund (Roll, 1992; Castañeda, 2007; and Castañeda and Rudolph, 2009). There is also evidence that pension funds display herding behavior (Raddatz and Schmukler, 2008).

\footnotetext{
${ }^{28}$ This is even more striking when one considers that mutual fund redemptions can be systemic aside from idiosyncratic (investors may massively pull out of all mutual funds when market conditions worsen). See Kaminsky et al. (2004). The systemic nature of mutual fund redemptions makes liquidations by mutual funds more costly as all funds liquidate their positions at the same time.
} 
As a second piece of evidence to highlight the role of underlying investors, we compare the maturity structure of Chilean mutual funds that invest in Chile (domestic mutual funds) to that of Chilean mutual funds that invest in emerging economies. The latter are targeted to different underlying Chilean investors. Those investing in emerging economies are probably targeted to investors that are wealthier, more sophisticated, and more willing to take on risk and seek higher returns, in comparison to investors that prefer to invest only domestically. Figure 12 shows that, mutual funds investing in emerging markets are slightly more long term that those investing in Chile. For example, domestic mutual funds invest $38 \%$ of their portfolio up to one year, $59 \%$ up to three years, and $88 \%$ up to ten years, compared to $20 \%, 52 \%$, and $99 \%$ in the case of mutual funds that only invest in emerging economies. While the portfolios of these two groups of investors have a similar average maturity and the hypothesis that they have the same maturity structure can only be rejected at the $10 \%$ significance level, the share invested in assets with maturities of less than one year and more than ten years are significantly different at conventional levels.

A second factor that might affect incentives is the structure of liabilities. To test its importance, we analyze insurance companies. Unlike mutual and pension funds, insurance companies have long-term liabilities as they mostly provide annuities for pensioners and life insurance; moreover, they are not evaluated on a short-term return basis by investors that can pull out their funds.

Figure 13 shows the maturity structure of Chilean insurance companies. The figure shows that insurance providers are much more heavily invested in long-term instruments than mutual and pension funds are. The differences are quite startling. For 
example, Chilean insurance companies invest $31 \%$ of their holdings up to three years, $38 \%$ up to five years, and 52\% up to ten years, compared to Chilean PFAs that invest $60 \%$ up to three years, $79 \%$ up to five years, and $96 \%$ up to ten years, and to Chilean mutual funds that invest $59 \%$ up to three years, $73 \%$ up to five years, and $88 \%$ up to ten years. These differences are also reflected on the average maturity of Chilean insurance companies (10.32 years) relative to that of mutual and pension funds (3.88 and 3.16 years, respectively). Even compared to US mutual funds, Chilean insurance companies are more long term. For example, US multi-sector mutual funds invest $24 \%$ up to three years, $37 \%$ up to five years, and $72 \%$ up to ten years, and US short-term mutual funds invest $48 \%$ up to three years, $64 \%$ up to five years, and $75 \%$ up to ten years.

In sum, the evidence suggests that the structure of liabilities matters significantly. Merely the shift from being asset managers to being asset-liability managers sharply changes the maturity structure of investments. This comparison is powerful because insurance companies face the same universe of available assets. So changing the incentive structure seems to push managers to invest long term, even in emerging markets. Furthermore, the comparison with insurance companies reinforces the conclusion that it is not the availability of instruments what makes mutual and pension funds invest short term.

\section{Conclusions}

Using the case of Chilean institutional investors and US mutual funds, this paper studies to what extent emerging market investors invest long term and the factors that affect their decisions to hold assets at different maturities. This analysis provides a valuable benchmark for how long the debt maturity structure can be extended in 
emerging economies. Chilean institutional investors are sophisticated investors and are mostly expected to invest long term. Moreover, Chile has relatively developed capital markets and has made a conscious effort to try to extend debt maturities through a broad range of reforms.

The paper finds that, despite all the favorable conditions, asset managers in Chile are significantly tilted toward the short term, with a large portion of their portfolio in very liquid assets. This contrasts with the maturity structure of US mutual funds. Regarding the factors that might be driving the short-termism, the paper rejects two hypotheses as determinants of the maturity structure. First, asset managers choose short-term instruments even when assets for long-term investments are widely available, that is, the supply side of instruments is not a constraint. On the contrary, the investor side (the supply side of funds) seems essential to understand debt maturity structures. Second, evidence from pension funds suggests that institutional investors do not hold short-term instruments for tactical reasons to take advantage of buying opportunities or as a response to shocks.

At least two factors seem to play an important role in shaping investor demand and, consequently, the maturity structure of institutional investors. The first one is the risk profile of available instruments. Mutual and pension funds invest more long term in indexed and hard-currency instruments, which yield less volatile returns. However, this cannot be the only driver because Chilean fund managers are more tilted toward the short term than US funds even when controlling for the assets in which they invest. For example, when comparing Chilean and US mutual funds investing only in emerging 
economies, the maturity structure of US funds is much more long term than that of Chilean funds.

The second factor that seems to have an even greater role on the maturity structure is incentives. Incentives can take on many forms, but two that the paper shows to be very relevant are the behavior of underlying investors and the liability structure of asset managers. First, Chilean mutual funds are more subject to investor redemptions than US mutual funds are, which can explain part of their short-termism. Moreover, Chilean mutual funds invest more long term when investing in other emerging markets; Chilean investors purchasing shares in emerging market funds tend to be more sophisticated and seek higher returns than those investing domestically. This evidence suggests that mutual fund managers are sensitive to the underlying investors and that the investment horizon choices they make might be influenced by this factor. Second, asset managers (those of mutual and pension funds) do not have liabilities, and thus have incentives to invest in short-term assets that are less risky and, as a consequence, reduce the likelihood of deviating from their peers (which minimizes the probability of punishment through further outflows or less future inflows). In contrast, insurance companies have long-term liabilities and, as a result, the maturity structure of their assets is significantly more long term. In other words, given that asset managers and asset-liability managers face the same investment opportunities, the exercise shows the important role of incentives in shifting the maturity structure of assets, and further rejects the role of the supply side of instruments.

To conclude, despite the benefits of long-term debt, emerging economies seem to face an uphill effort in extending debt maturities, even when many of the ex-ante 
conditions are in place. In particular, extending debt maturities by just developing institutional investors such as mutual and pension funds seems very difficult to achieve and runs contrary to many of the initial expectations. However, two factors might help. First, a reduction of systemic risk and the provision of instruments that hedge those risks might help investors feel more secure to move long in their maturity choices. While reducing systemic risk seems to be welfare improving, providing hedges might just entail a transfer of risk from creditors to debtors (de la Torre and Schmukler, 2004). How this risk is distributed in the economy is material for further research. Second, having the right incentives seems crucial for manager behavior. Merely establishing assetmanagement institutions and assuming that managers will invest long term does not appear to yield the expected outcome. Moreover, there seems to be a strong tradeoff between monitoring managers according to their short-term performance (which leads to short-term investments), on the one hand, and obtaining higher returns and incurring higher risks by investing long term, on the other hand. The socially optimal design to balance this tradeoff is not obvious (Acemoglu et al., 2007) and requires further research. 


\section{References}

Acemoglu, D., M. Kremer, and A. Mian, 2007. Incentives in Markets, Firms, and Governments, Journal of Law, Economics, and Organization 24(2), 273-306.

Aguiar, M. and G. Gopinath, 2005. Fire-Sale Foreign Direct Investment and Liquidity Crises, Review of Economics and Statistics 87(3), 439-452.

Alfaro, L. and F. Kanczuk, 2006. Sovereign Debt: Indexation and Maturity, InterAmerican Development Bank Working Paper 560.

Alfaro, L. and F. Kanczuk, 2009. Debt Maturity: Is Long-Term Debt Optimal? Review of International Economics, forthcoming.

Allen, F. and E. Carletti, 2008. Mark-to-Market Accounting and Liquidity Pricing, Journal of Accounting and Economics 45(2-3), 358-378.

Allen, F. and D. Gale, 1994. Limited Market Participation and Volatility of Asset Prices, American Economic Review 84(4), 933-955.

Allen, F. and D. Gale, 1998. Optimal Financial Crises, Journal of Finance 53(4), 1,2451,284 .

Barro, R., 1997. Optimal Debt Management of Indexed and Nominal Debt, Annals of Economics and Finance 4(1), 1-5.

Bebchuk, L. and L. Stole, 1993. Do Short-Term Objectives Lead to Under- or Overinvestment in Long-Term Projects? Journal of Finance 48(2), 719-729.

Benjamini, Y. and D. Yekutieli, 2001. The Control of the False Discovery Rate in Multiple Testing under Dependency, Annals of Statistics 29(4), 1165-1188.

Blanchard, O. and A. Missale, 1994. The Debt Burden and Debt Maturity, American Economic Review 84(1), 309-319.

Bleakley, H. and K. Cowan, 2005. Maturity Mismatch and Financial Crises: Evidence from Emerging Market Corporations, Proceedings, Federal Reserve Bank of San Francisco.

Bleakley, H. and K. Cowan, 2008. Corporate Dollar Debt and Depreciations: Much Ado about Nothing? Review of Economic Statistics 90(4), 612-626.

Borensztein, E., M. Chamon, O. Jeanne, P. Mauro and J. Zettelmeyer, 2005. Sovereign Debt Structure for Crisis Prevention, IMF Occasional Paper 237.

Borensztein, E., E. Levy Yeyati, and U. Panizza, IADB, 2006. Living with Debt: How to Limit the Risks of Sovereign Finance, Harvard University Press, Cambridge, MA.

Braun, M. and I. Briones, 2008. Development of the Chilean Corporate Bond Market, in Eichengreen B., U. Panizza, and E. Borensztein (Eds.), The Development of the Latin American Bond Markets, MIT Press.

Bolton, P., J. Scheinkman, and W. Xiong, 2006. Executive Compensation and ShortTermist Behavior in Speculative Markets, Review of Economic Studies 73(3), 577-610.

Broner, F., G. Lorenzoni, and S. Schmukler, 2007. Why Do Emerging Economies Borrow Short Term? NBER Working Paper 13076.

Buiter, W. and A. Sibert, 2008. The Icelandic Banking Crisis and What to Do about It: The Lender of Last Resort Theory of Optimal Currency Areas, CEPR Policy Insight 26. 
Calomiris, C., 2008. The Subprime Turmoil, What's Old, What's New, and What's Next, in Maintaining Stability in a Changing Financial System, Federal Reserve Bank of Kansas City Jackson Hole Symposium.

Calvo, G., 1988. Servicing the Public Debt: The Role of Expectations, American Economic Review 78(4), 647-661.

Campbell, J., M. Lettau, B. Malkiel, and Y. Xu, 2001. Have Individual Stocks Become More Volatile? An Empirical Exploration of Idiosyncratic Risk, Journal of Finance 56(1), 1-43.

Campbell, J. and L.M. Viceira, 2002. Strategic Asset Allocation: Portfolio Choice for Long-Term Investors, Oxford University Press, Oxford.

Castañeda, P., 2007. Long Term Risk Assessment in a Defined Contribution Pension System, Superintendencia de Pensiones, Chile.

Castaneda, P. and H. Rudolph, 2009, Portfolio Choice, Minimum Return Guarantees, and Competition in DC Pension Systems, SSRN Working Paper 1405411.

Cerda, R., 2005. Does Social Security Affect Retirement and Labor Supply? Evidence from Chile, Developing Economies 43(2), 235-264.

Chang, R. and A. Velasco, 1999. Liquidity Crises in Emerging Markets: Theory and Policy, in Bernanke, B. and J. Rotemberg (Eds.), NBER Macroeconomics Annual 1999 , MIT Press, Cambridge, MA.

Chevalier, J. and G. Ellison, 1999. Career Concerns of Mutual Fund Managers, Quarterly Journal of Economics 114(2), 389-432.

Claessens, S., S. Djankov, and L. Xu, 2000. Corporate Performance in the East Asian Financial Crisis, World Bank Research Observer 15(1), 23-46.

Cuesta-Albertos, J.A., R. Fraiman, A. Galves, J. Garcia, and M. Svarc, 2007. Identifying Rhythmic Classes of Languages Using Their Sonority: A Kolmogorov-Smirnov Approach, Journal of Applied Statistics 34, 749-761.

Cuesta-Albertos, J.A., R. Fraiman, and T. Ransford, 2006. Random Projections and Goodness-of-Fit Tests in Infinite-Dimensional Spaces. Bulletin of the Brazilian Mathematical Society 37(4), 1-25.

de la Torre, A., J.C. Gozzi, and S. Schmukler, 2007. Financial Development: Emerging and Maturing Policy Issues, World Bank Research Observer 22(1), 67-102.

de la Torre, A. and S. Schmukler, 2004. Coping with Risks Through Mismatches: Domestic and International Financial Contracts for Emerging Economies, International Finance 7(3), 349-90.

Eichengreen, B. and R. Hausmann, 1999. Exchange Rates and Financial Fragility, Proceedings, Federal Reserve Bank of Kansas City, 329-368.

Jin, L. and L. Kogan, 2008. Managerial Career Concern and Mutual Fund ShortTermism, mimeo, Harvard Business School and MIT Sloan School of Management.

Jeanne, O., 2009. Debt Maturity and the International Financial Architecture, American Economic Review, forthcoming.

Kaminsky, G., R. Lyons, and S. Schmukler, 2004. Managers, Investors, and Crises: Mutual Fund Strategies in Emerging Markets, Journal of International Economics 64(1), 113-134.

Kapur, S. and A. Timmermann, 2005. Relative Performance Evaluation Contracts and Asset Market Equilibrium, Economic Journal 115(506), 1,077-1,102. 
Krugman, P., 1998. Fire-sale FDI, http://web.mit.edu/krugman/www/FIRESALE.htm.

Raddatz, C. and S. Schmukler, 2008. Pension Funds and Capital Market Development: How Much Bang for the Buck? World Bank Policy Research Working Paper 4787.

Radelet, S. and J. Sachs, 1998. The East Asian Financial Crisis: Diagnosis, Remedies, Prospects, Brookings Papers on Economic Activity 1, 1-74.

Rajan, R., 2005. Has Financial Development Made the World Riskier? Proceedings, Federal Reserve Bank of Kansas City, 313-369.

Rodrik, D. and A. Velasco, 2000. Short-Term Capital Flows, in Pleskovic, B. and J. Stiglitz (Eds.), Annual World Bank Conference on Development Economics 1999, World Bank, Washington, DC.

Roll, R., 1992. A Mean/Variance Analysis of Tracking Error, Journal of Portfolio Management 18(4), 13-22.

Schmukler, S. and E. Vesperoni, 2006. Financial Globalization and Debt Maturity in Emerging Economies, Journal of Development Economics 79(1), 183-207.

Sharfstein, D. and J. Stein, 1990. Herd Behavior and Investment, American Economic Review 80(3), 465-479.

Shleifer, A. and R. Vishny, 1990. Equilibrium Short Horizons of Investors and Firms, American Economic Review 80(2), 148-153.

Stein, J., 2005. Why Are Most Funds Open-End? Competition and the Limits of Arbitrage, Quarterly Journal of Economics 120(1), 247-272.

The Economist, 1999. Survey of Global Finance: Time for a Redesign, January 28, 1999.

Tirole, J., 2003. Inefficient Foreign Borrowing: A Dual- and Common-Agency Perspective, American Economic Review 93(5), 1,678-1,702. 


\section{Figure 1 \\ Maturity Structure of Chilean Mutual Funds}

This figure presents the maturity structure of Chilean domestic bond mutual funds, that is, the proportion of the portfolio held at different terms to maturity. Shares are calculated as a fraction of the overall portfolio. Only medium- and long-term bond mutual funds are taken into account. The maturity structure is calculated per mutual fund and averaged across funds at each moment in time using monthly bins, and then averaged over time. The sample period is Sep. 2002 to Dec. 2005 . Panel A shows the average accumulated portfolio weight in each bin as well as the 25th and 75th percentiles across mutual funds. Panel B shows the average total portfolio weight within each monthly bin, along with the fitted value of the fractional polynomial regression of total portfolio weights on the term to maturity in months. Panel C shows the accumulated weights in a table format.
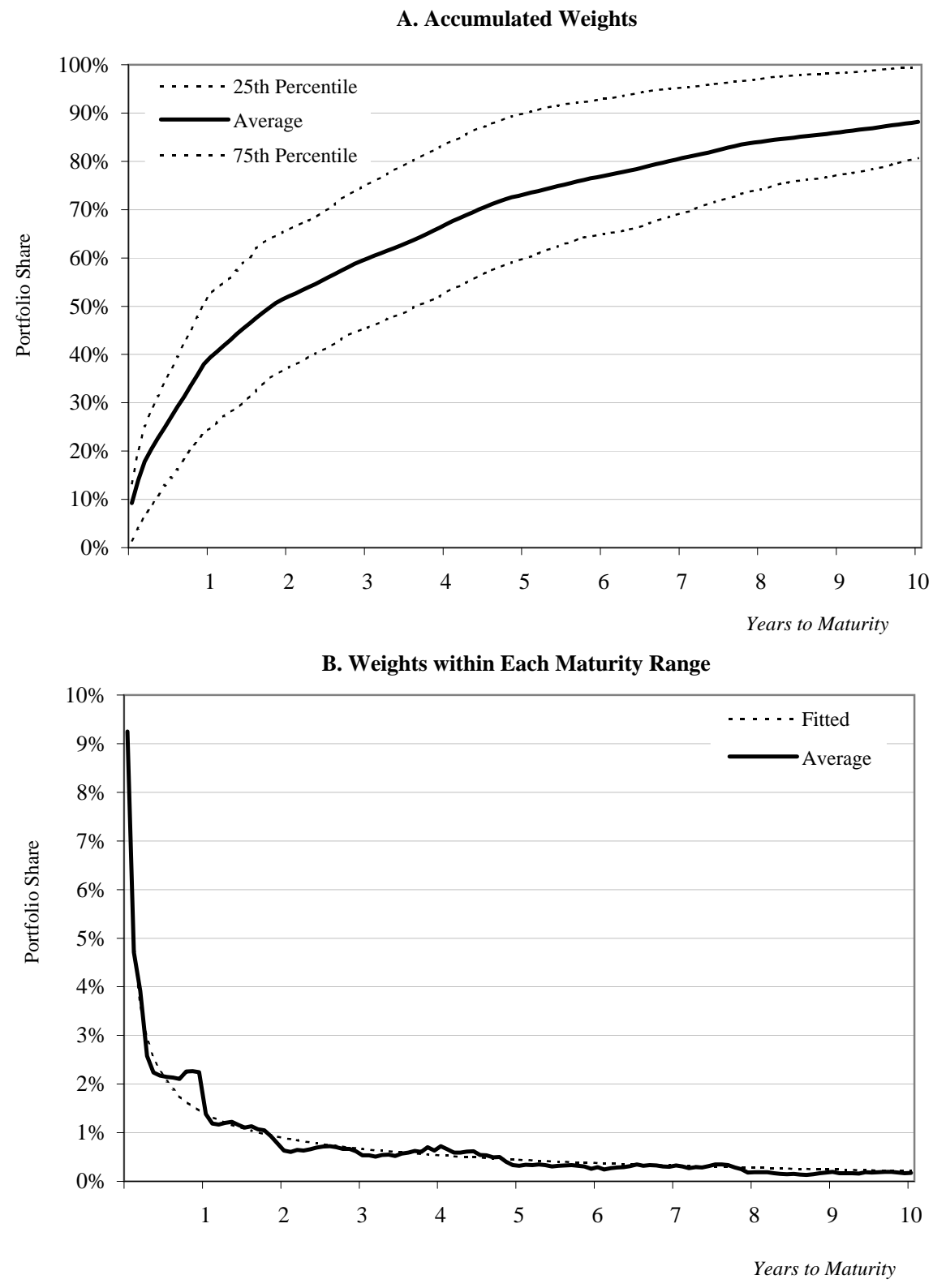

C. Accumulated Weights

\begin{tabular}{|c|c|c|c|c|c|c|c|c|}
\hline & $<$ 1year (y) & $<3 y$ & $<5 y$ & $<7 \mathrm{y}$ & $<10 \mathrm{y}$ & $<15 y$ & $<20 \mathrm{y}$ & $<30 y$ \\
\hline Chilean Domestic Mutual Funds & $38 \%$ & $59 \%$ & $73 \%$ & $80 \%$ & $88 \%$ & $95 \%$ & $99 \%$ & $100 \%$ \\
\hline
\end{tabular}


Figure 2

\section{Maturity Structure of Chilean PFAs}

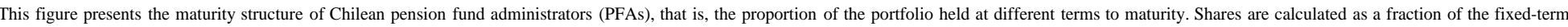

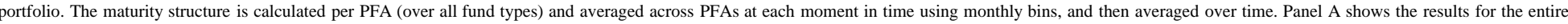

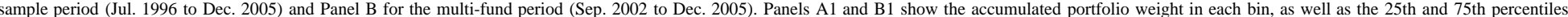

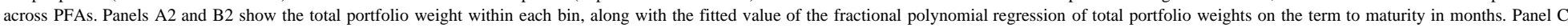
shows the accumulated weights in a table format.

A. Entire Sample Period

A1. Accumulated Weights

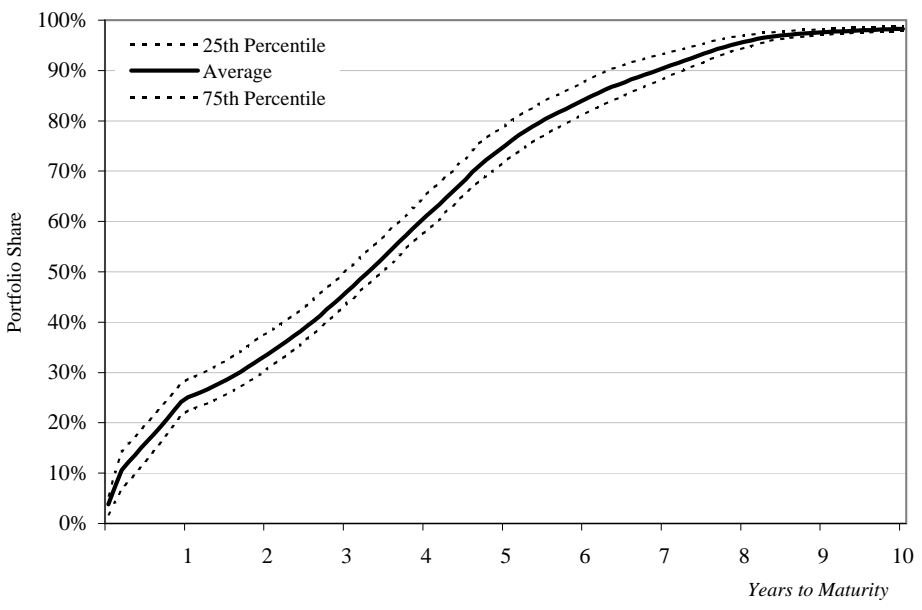

A2. Weights within Each Maturity Range

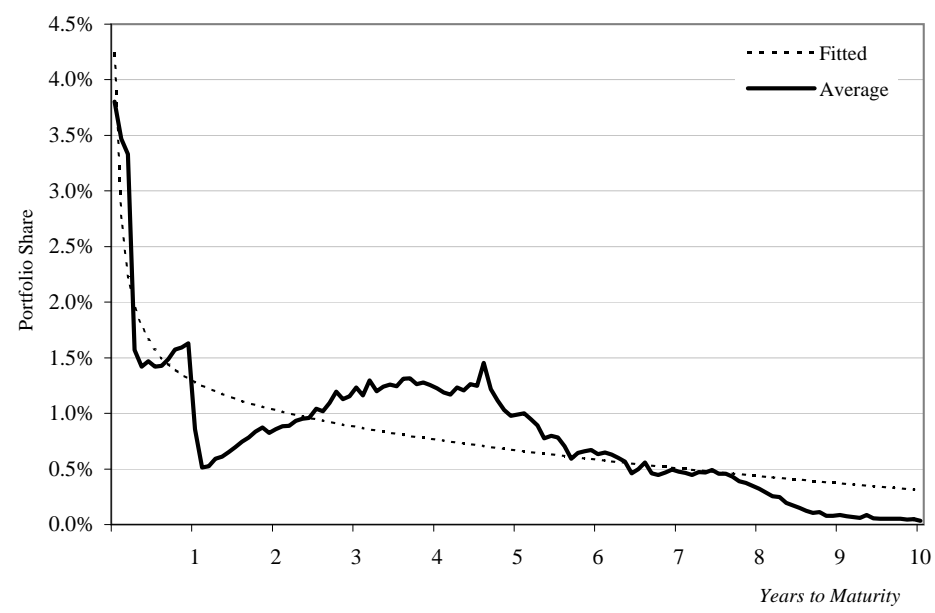

B. Multi-Fund Period

B1. Accumulated Weights

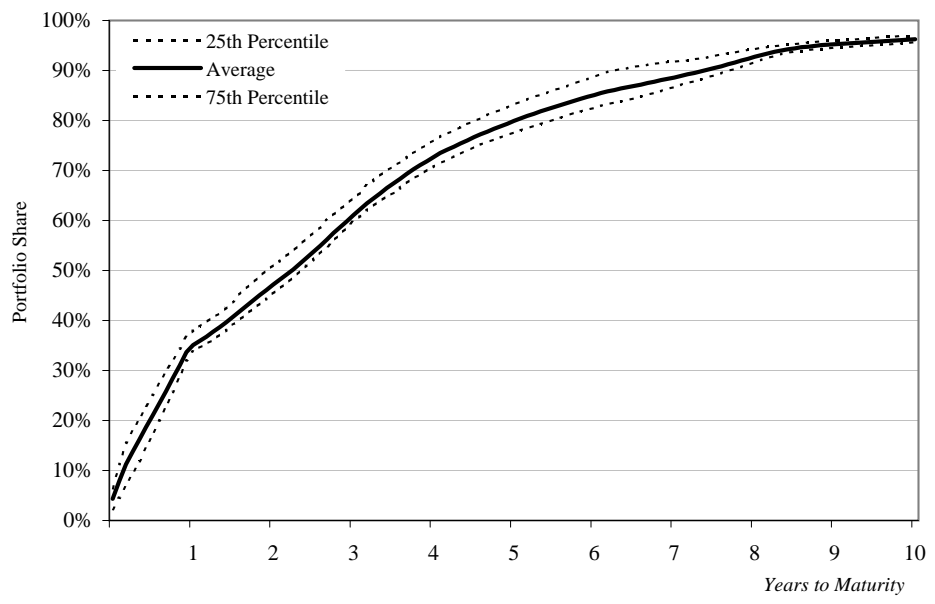

B2. Weights within Each Maturity Range

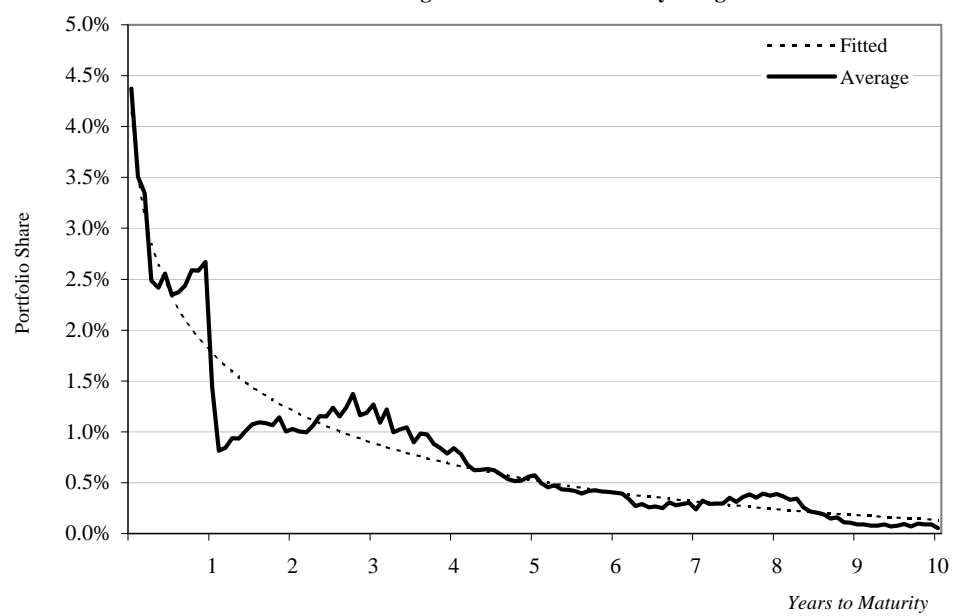

\section{Accumulated Weights}

\begin{tabular}{|c|c|c|c|c|c|c|c|c|}
\hline & $<1$ year $(\mathrm{y})$ & $<3 y$ & $<5 y$ & $<7 \mathrm{y}$ & $<10 \mathrm{y}$ & $<15 y$ & $<20 \mathrm{y}$ & $<30 \mathrm{y}$ \\
\hline Chilean PFAs - Entire Sample Period & $24 \%$ & $45 \%$ & $74 \%$ & $90 \%$ & $98 \%$ & $100 \%$ & $100 \%$ & $100 \%$ \\
\hline Chilean PFAs - Multi-Fund Period & $34 \%$ & $60 \%$ & $79 \%$ & $88 \%$ & $96 \%$ & $100 \%$ & $100 \%$ & $100 \%$ \\
\hline
\end{tabular}




\section{Figure 3}

\section{Maturity Structure of Chilean Domestic Mutual Funds and PFAs}

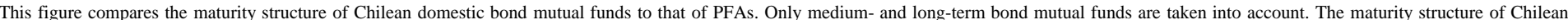

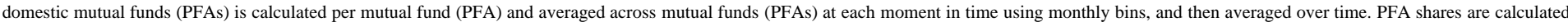

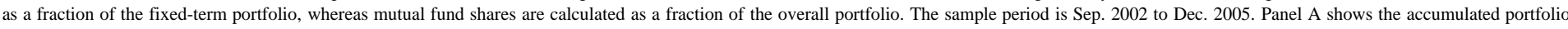

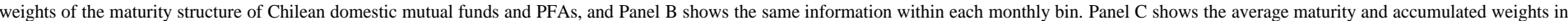

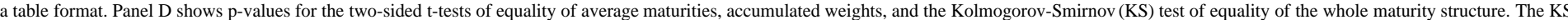

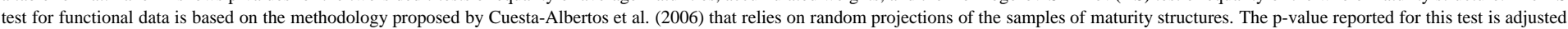

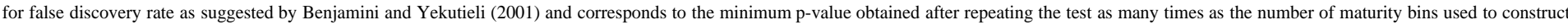
the figure, using a different random projection vector in each repetition. *, **, and *** represent statistical significance at the $10 \%, 5 \%$, and $1 \%$ level, respectively.

A. Accumulated Weights

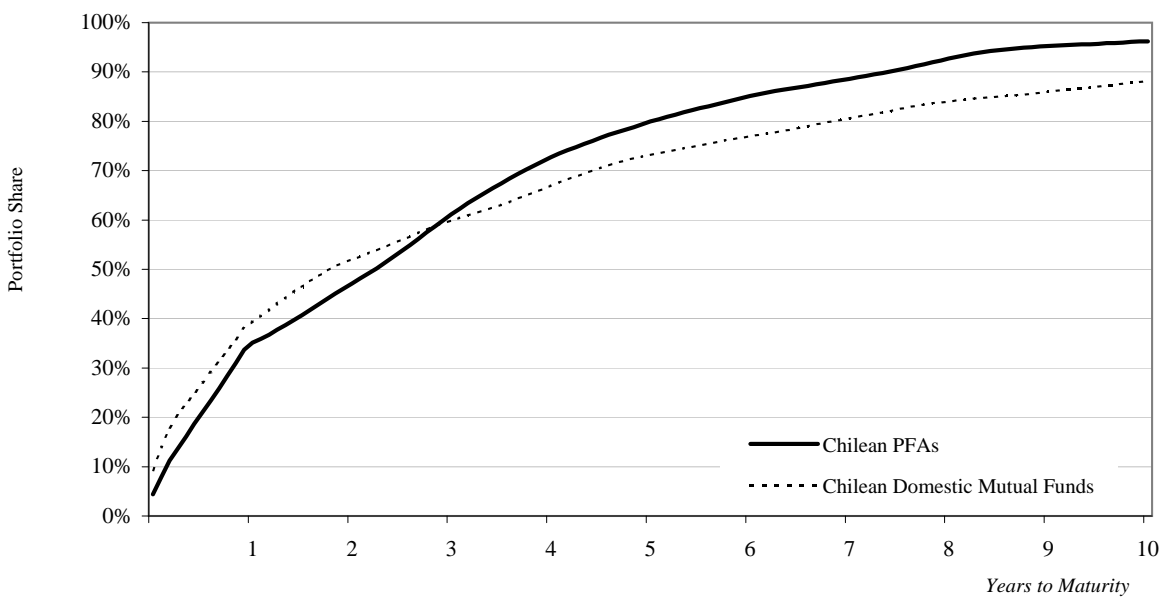

B. Weights within Each Maturity Range

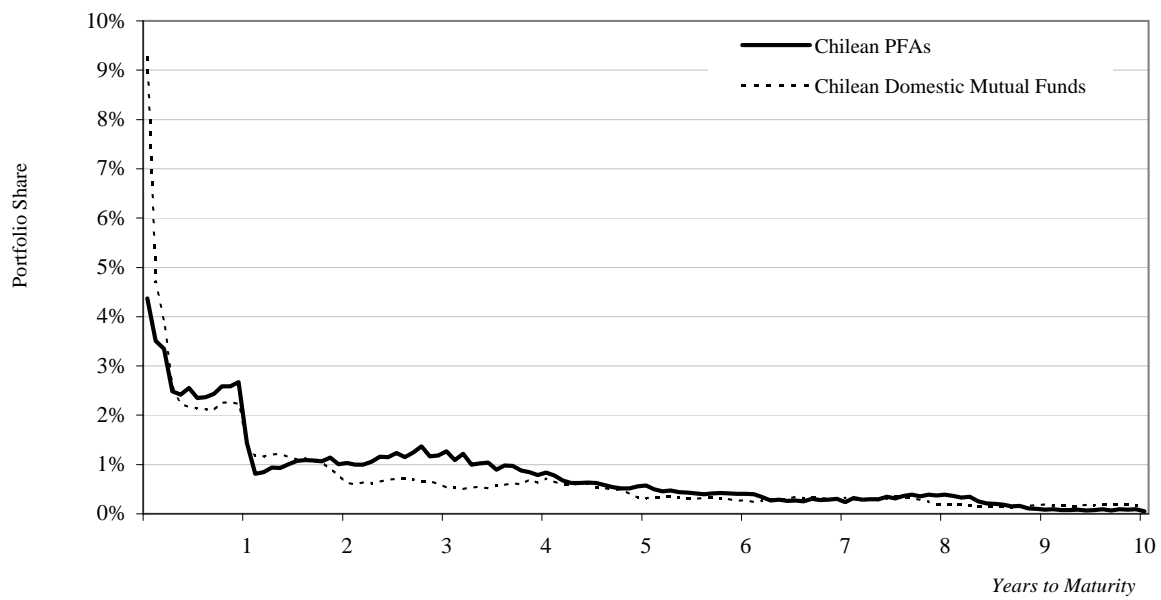

C. Average Maturity and Accumulated Weights

\begin{tabular}{|c|c|c|c|c|c|c|c|c|c|}
\hline & (i) & (ii) & (iii) & (iv) & (v) & (vi) & (vii) & (viii) & (ix) \\
\hline & & \multicolumn{8}{|c|}{ Accumulated Weights } \\
\hline & Avg. Maturity & $<$ 1year (y) & $<3 y$ & $<5 y$ & $<7 \mathrm{y}$ & $<10 \mathrm{y}$ & $<15 y$ & $<20 y$ & $<30 y$ \\
\hline (1) Chilean Domestic Mutual Funds & 3.88 & $38 \%$ & $59 \%$ & $73 \%$ & $80 \%$ & $88 \%$ & $95 \%$ & $99 \%$ & $100 \%$ \\
\hline (2) Chilean PFAs & 3.16 & $34 \%$ & $60 \%$ & $79 \%$ & $88 \%$ & $96 \%$ & $100 \%$ & $100 \%$ & $100 \%$ \\
\hline \multicolumn{10}{|l|}{ D. Hypothesis Testing } \\
\hline & (i) & (ii) & (iii) & (iv) & (v) & (vi) & (vii) & (viii) & (ix) \\
\hline & & \multicolumn{8}{|c|}{ Accumulated Weights } \\
\hline & Avg. Maturity & $<1$ year (y) & $<3 y$ & $<5 y$ & $<7 \mathrm{y}$ & $<10 \mathrm{y}$ & $<15 y$ & $>20 \mathrm{y}$ & KS \\
\hline$(1)=(2)$ & 0.29 & 0.16 & 0.75 & 0.39 & 0.20 & $0.07^{*}$ & $0.03^{* *}$ & $0.10^{*}$ & $0.02 * *$ \\
\hline
\end{tabular}


Figure 4

Maturity Structure of Chilean Domestic Mutual Funds and PFAs Compared to US Mutual Funds

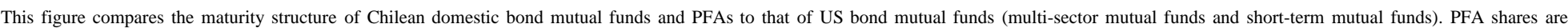

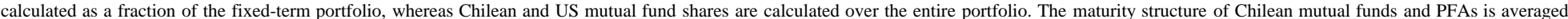

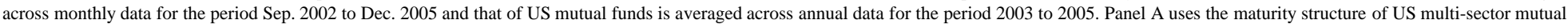

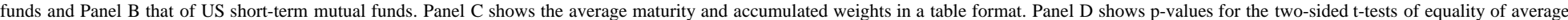

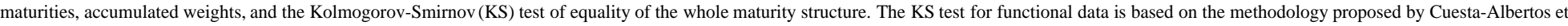

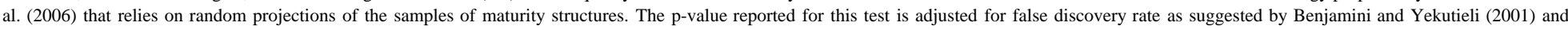

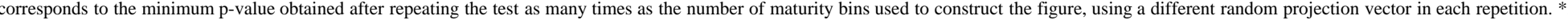
$* *$, and $* * *$ represent statistical significance at the $10 \%, 5 \%$, and $1 \%$ level, respectively.

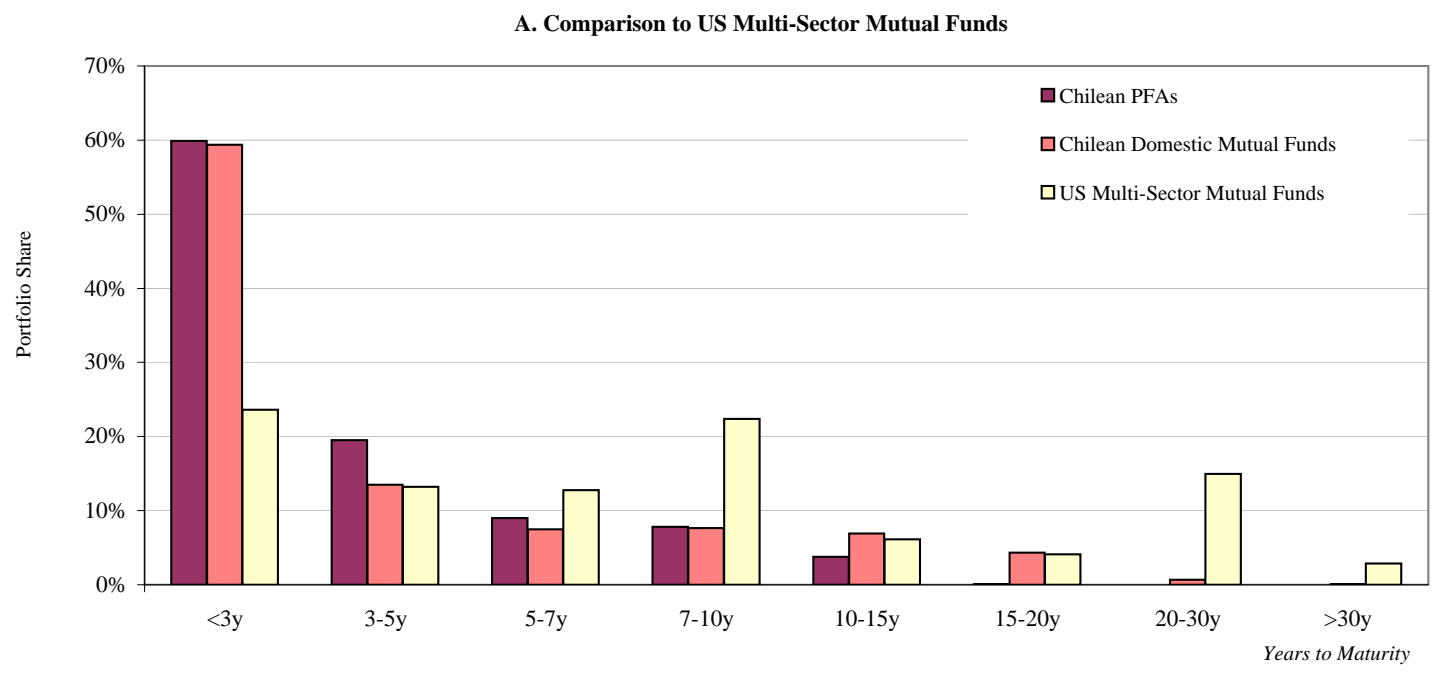

B. Comparison to US Short-Term Mutual Funds

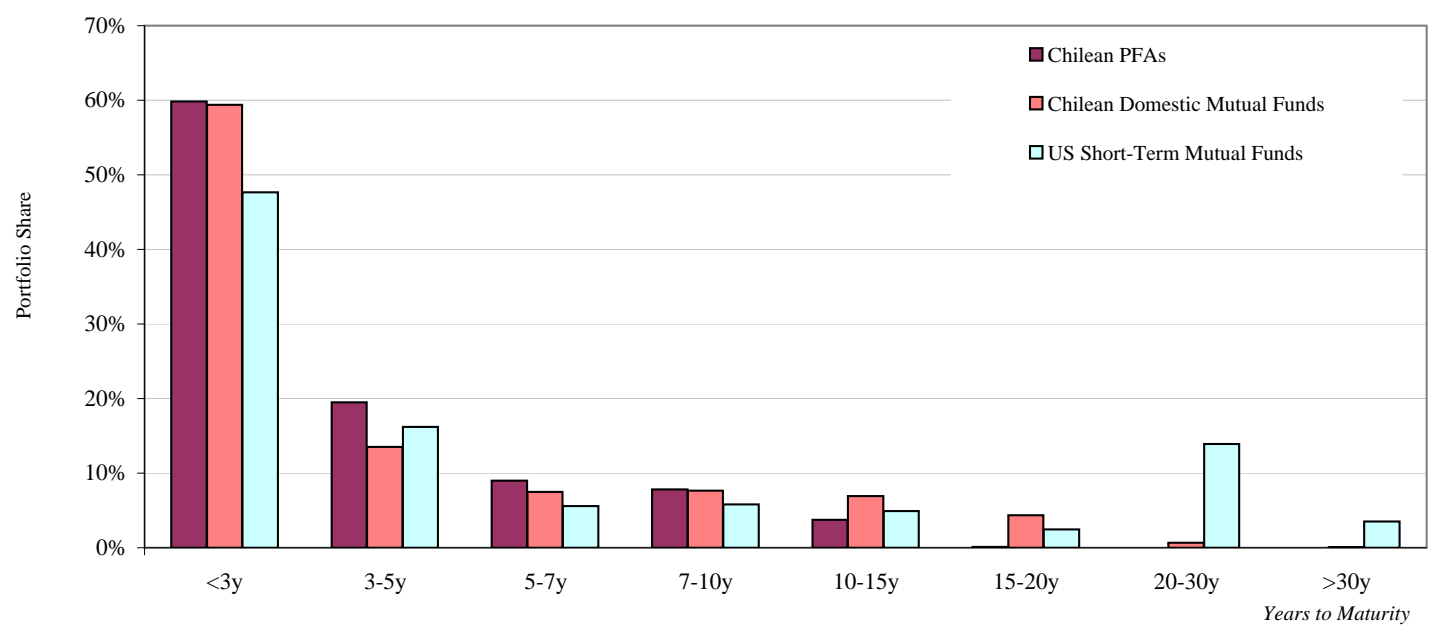

C. Average Maturity and Accumulated Weights

\begin{tabular}{|c|c|c|c|c|c|c|c|c|}
\hline & (i) & (ii) & (iii) & (iv) & (v) & (vi) & (vii) & (viii) \\
\hline & & \multicolumn{7}{|c|}{ Accumulated Weights } \\
\hline & Avg. Maturity & $<$ 3years (y) & $<5 y$ & $<7 y$ & $<10 y$ & $<15 y$ & $<20 y$ & $<30 y$ \\
\hline (1) Chilean Domestic Mutual Funds & 3.88 & $59 \%$ & $73 \%$ & $80 \%$ & $88 \%$ & $95 \%$ & $99 \%$ & $100 \%$ \\
\hline (2) Chilean PFAs & 3.16 & $60 \%$ & $79 \%$ & $88 \%$ & $96 \%$ & $100 \%$ & $100 \%$ & $100 \%$ \\
\hline (3) US Multi-Sector Mutual Funds & 9.55 & $24 \%$ & $37 \%$ & $50 \%$ & $72 \%$ & $78 \%$ & $82 \%$ & $97 \%$ \\
\hline (4) US Short-Term Mutual Funds & 7.76 & $48 \%$ & $64 \%$ & $69 \%$ & $75 \%$ & $80 \%$ & $83 \%$ & $96 \%$ \\
\hline \multicolumn{9}{|l|}{ D. Hypothesis Testing } \\
\hline & (i) & (ii) & (iii) & (iv) & (v) & (vi) & (vii) & (viii) \\
\hline & & \multicolumn{7}{|c|}{ Accumulated Weights } \\
\hline & Avg. Maturity & $<$ 3years (y) & $<5 y$ & $<7 y$ & $<10 \mathrm{y}$ & $<15 y$ & $>20 y$ & KS \\
\hline$(1)=(3)$ & $<0.01^{* * *}$ & $<0.01^{* * *}$ & $<0.01^{* * *}$ & $<0.01^{* * *}$ & $<0.01^{* * *}$ & $<0.01^{* * *}$ & $<0.01^{* * *}$ & $<0.01^{* * *}$ \\
\hline$(1)=(4)$ & $<0.01^{* * *}$ & $<0.01^{* * *}$ & $<0.01^{* * * *}$ & $<0.01^{* * *}$ & $<0.01^{* * *}$ & $<0.01^{* * *}$ & $<0.01^{* * *}$ & $<0.01 * * *$ \\
\hline$(2)=(3)$ & $<0.01^{* * *}$ & $<0.01 * * *$ & $<0.01 * * *$ & $<0.01^{* * *}$ & $<0.01^{* * *}$ & $<0.01^{* * * *}$ & $<0.01^{* * *}$ & $<0.01^{* * *}$ \\
\hline$(2)=(4)$ & $<0.01^{* * *}$ & 0.14 & $0.05^{* *}$ & $0.01^{* * *}$ & $<0.01^{* * * *}$ & $<0.01^{* * * *}$ & $<0.01^{* * *}$ & $<0.01^{* * *}$ \\
\hline
\end{tabular}


Figure 5

\section{Government Bonds Purchased by Chilean PFAs and Insurance Companies}

This figure presents the total amount of government bonds issued by currency denomination, plus the total amount and the proportion purchased by PFAs and insurance companies. See main text for a detailed explanation of the data. The panels are presented by currency and represent total issuances and purchases. The sample period is 1998 to 2008. Panel A shows the results for bonds denominated in nominal Chilean pesos, Panel B for bonds denominated in indexed (inflationlinked) Chilean pesos, and Panel C for bonds denominated in US dollars.

\section{A. Issuance Denominated in Nominal Chilean Pesos}

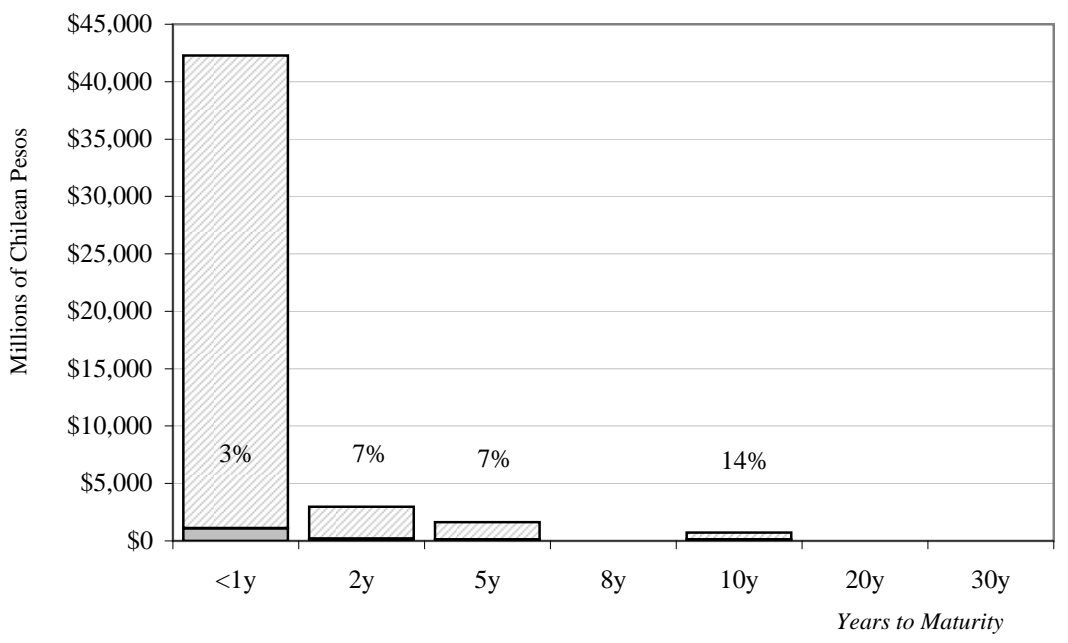

B. Issuance Denominated in Indexed Chilean Pesos

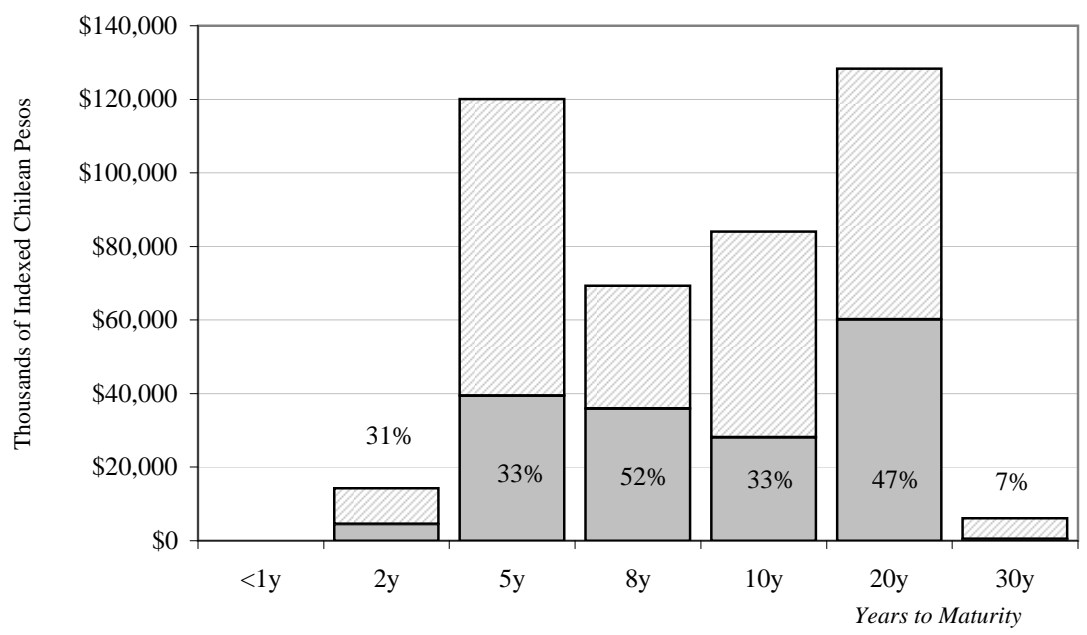

C. Issuance Denominated in US Dollars

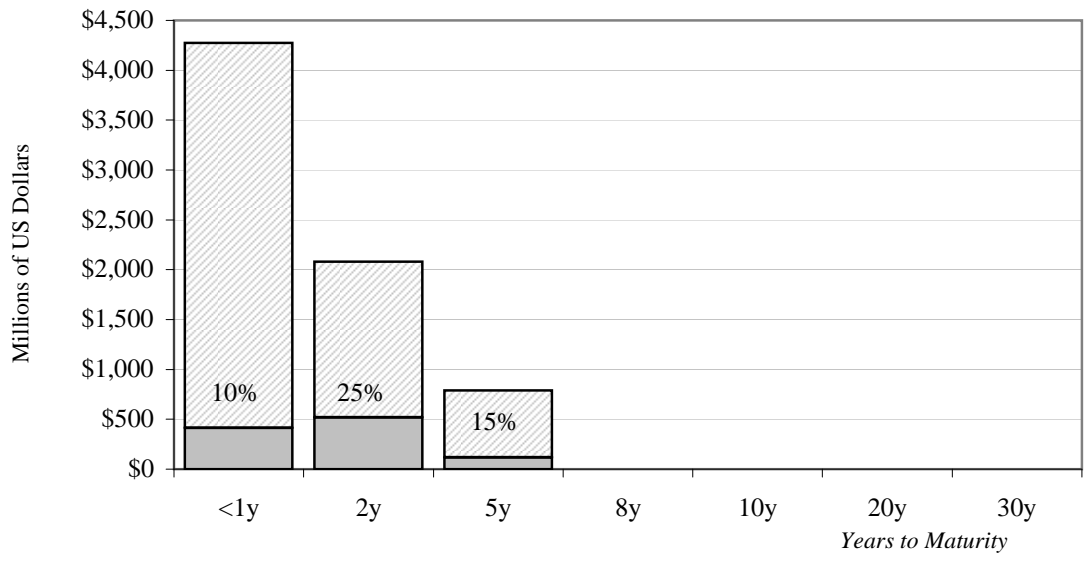

$\square$ Total Amount Purchased by PFAs and Insurance Companies $\square$ Total Issuance 
Figure 6

\section{Maturity Structure of Chilean Mutual Funds and PFAs Compared to US Mutual Funds Adjusting for Available Maturities}

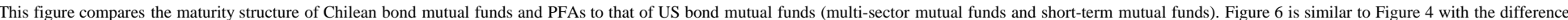

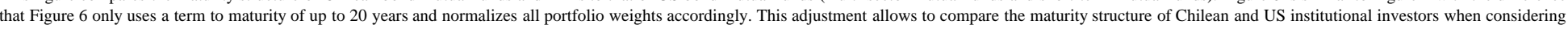

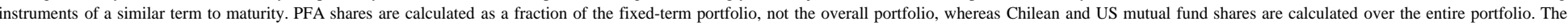

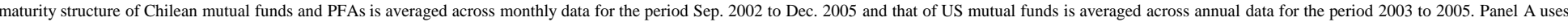

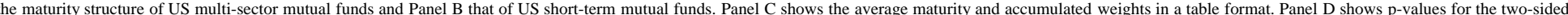

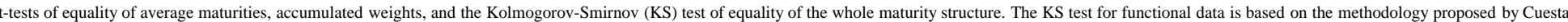

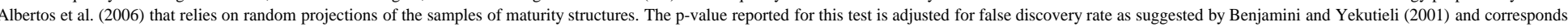

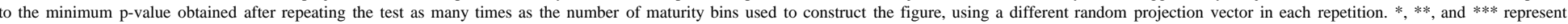
statistical significance at the $10 \%, 5 \%$, and $1 \%$ level, respectively.

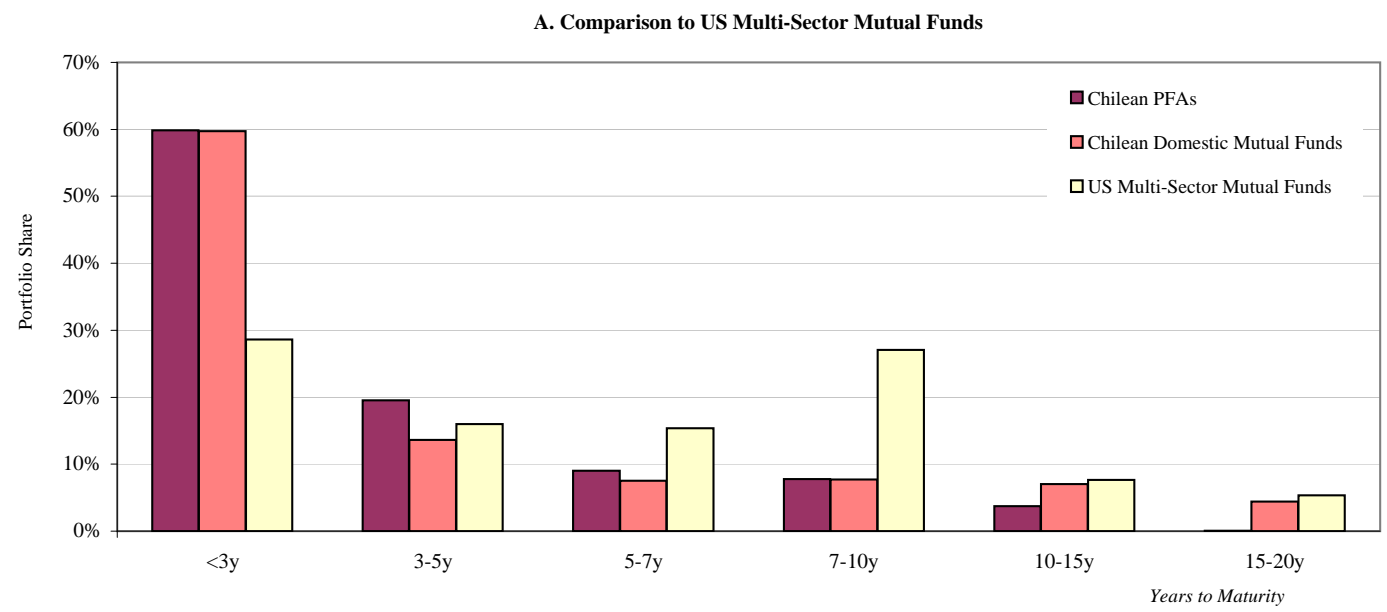

B. Comparison to US Short-Term Mutual Funds

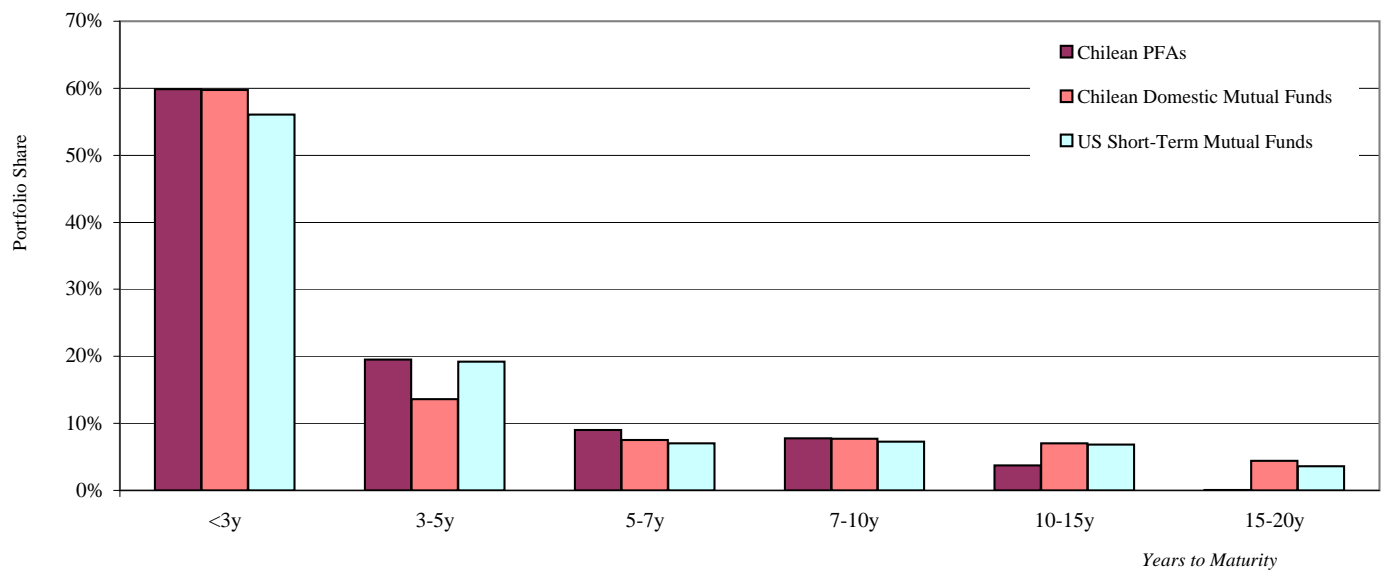

C. Average Maturity and Accumulated Weights

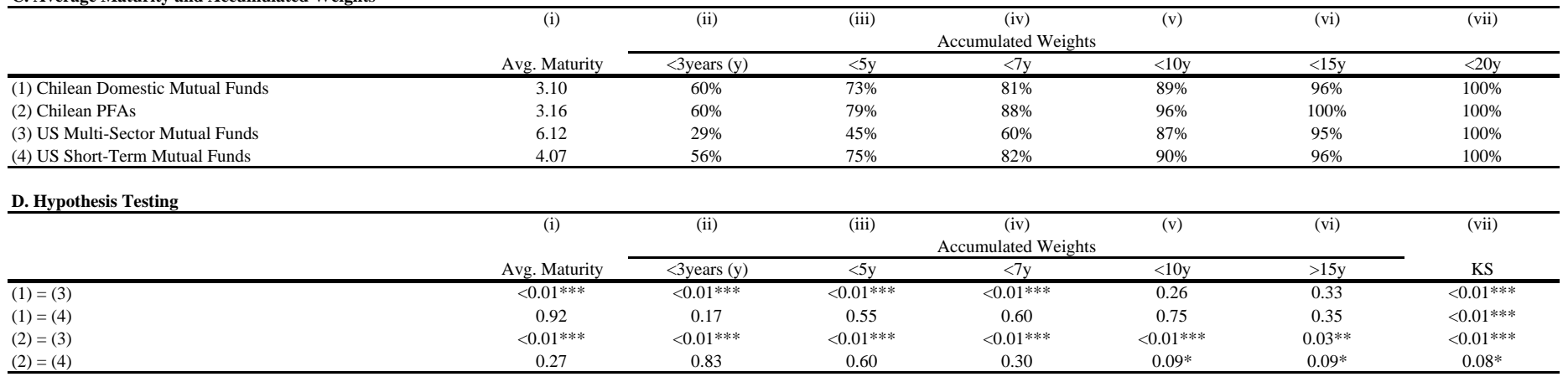


Figure 7

\section{Evolution of PFA Short-Term Assets around Events}

This figure shows how the share of short-term assets in the portfolio of PFAs varies during several events related to changes in the investment opportunities faced by PFAs. This figure presents the average share of domestic short-term fixed-income assets (those with a term to maturity of up to 30 days) held by Chilean PFAs. PFA shares are calculated as a fraction of the fixed-term portfolio, not the overall portfolio. Panel A shows the evolution of this share around six events in which regulatory constraints to investment abroad were relaxed during the period 2002 to 2008. The share is calculated per event at each moment in time as the average across PFAs using daily frequencies; the shares are then averaged across all six events. Panel B plots the same series during the Asian and Russian Crises of 1997-1998. Some of the major events occurring during this period are displayed in vertical lines.

A. Relaxation of Regulatory Constraints to Foreign Investment

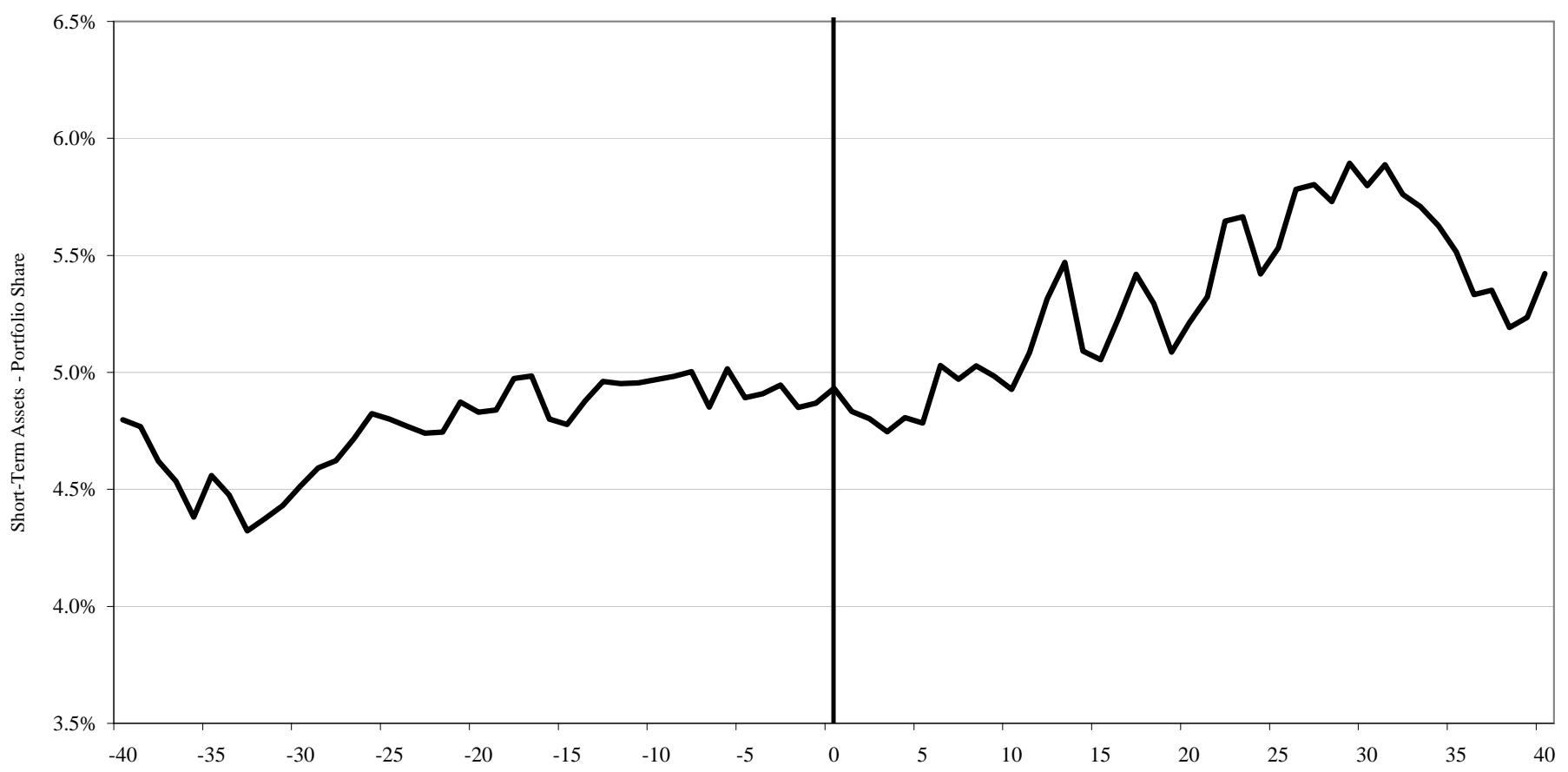

B. Asian and Russian Crises

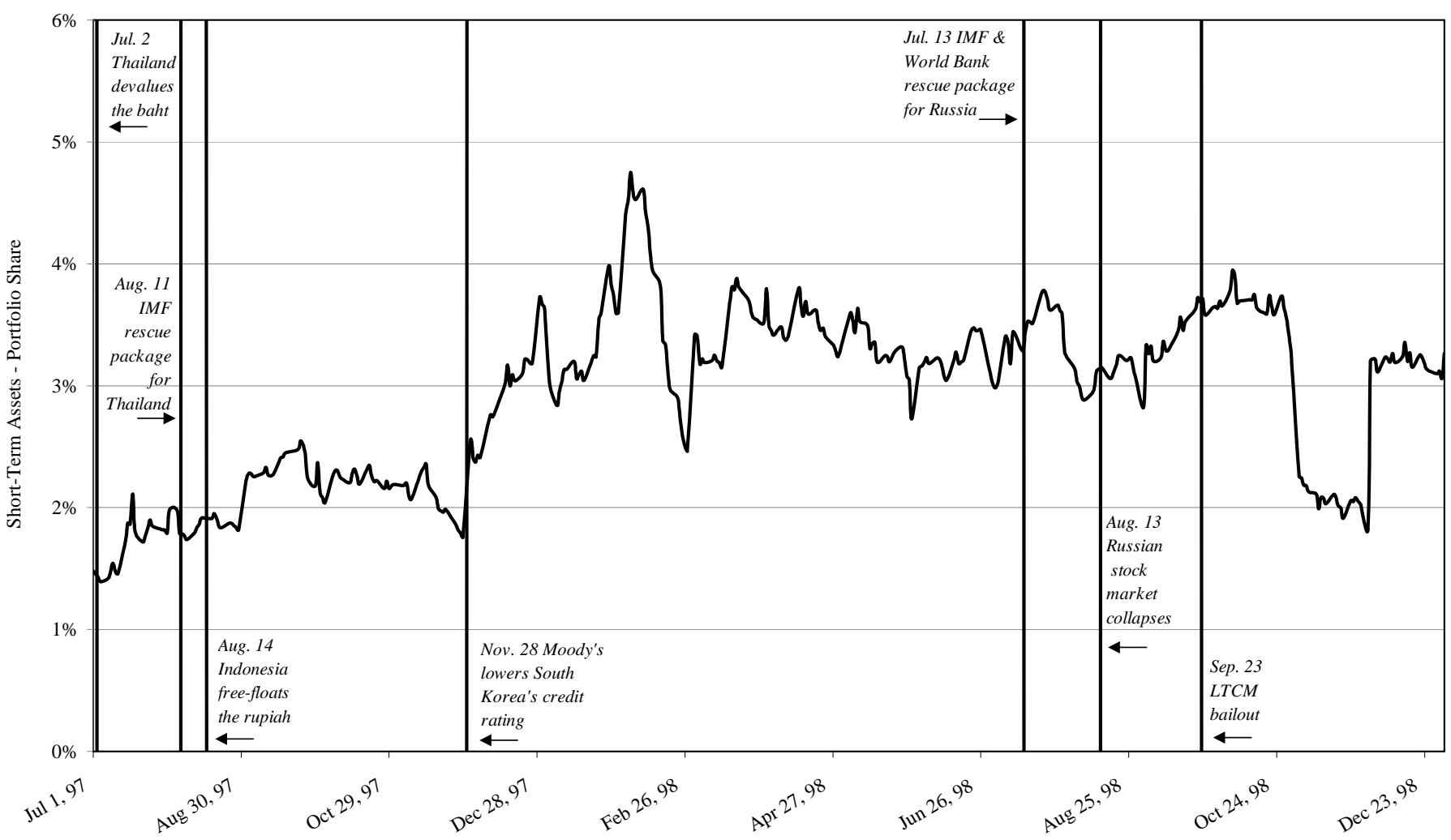


Figure 8

\section{Maturity Structure of Chilean Mutual Funds and PFAs by Currency}

This figure presents the maturity structure of Chilean domestic bond mutual funds and PFAs by currency: nominal Chilean pesos, indexed (inflation-linked) Chilean pesos, and "hard currencies" (US dollars, yens, euros, and British pounds). The maturity structure of Chilean mutual funds (PFAs) is calculated per mutual fund (PFA), respectively, and averaged across mutual funds (PFAs) at each moment in time using monthly bins. Weights are calculated over the entire portfolio and then normalized within each currency category. The sample period is Sep. 2002 to Dec. 2005. Panel A shows the maturity structure of Chilean domestic mutual funds and Panel B shows that of Chilean PFAs. Panel C shows the portfolio composition by currency. Panel D shows the average maturity by currency. Panel E shows p-values for the two-sided t-tests of equality of average maturities and the Kolmogorov-Smirnov (KS) test of equality of the whole maturity structure. The KS test for functional data is based on the methodology proposed by Cuesta-Albertos et al. (2006) that relies on random projections of the samples of maturity structures. The p-value reported for this test is adjusted for false discovery rate as suggested by Benjamini and Yekutieli (2001) and corresponds to the minimum p-value obtained after repeating the test as many times as the number of maturity bins used to construct the figure, using a different random projection vector in each repetition. *, **, and *** represent statistical significance at the $10 \%, 5 \%$, and $1 \%$ level, respectively.

A. Chilean Domestic Mutual Funds by Currency

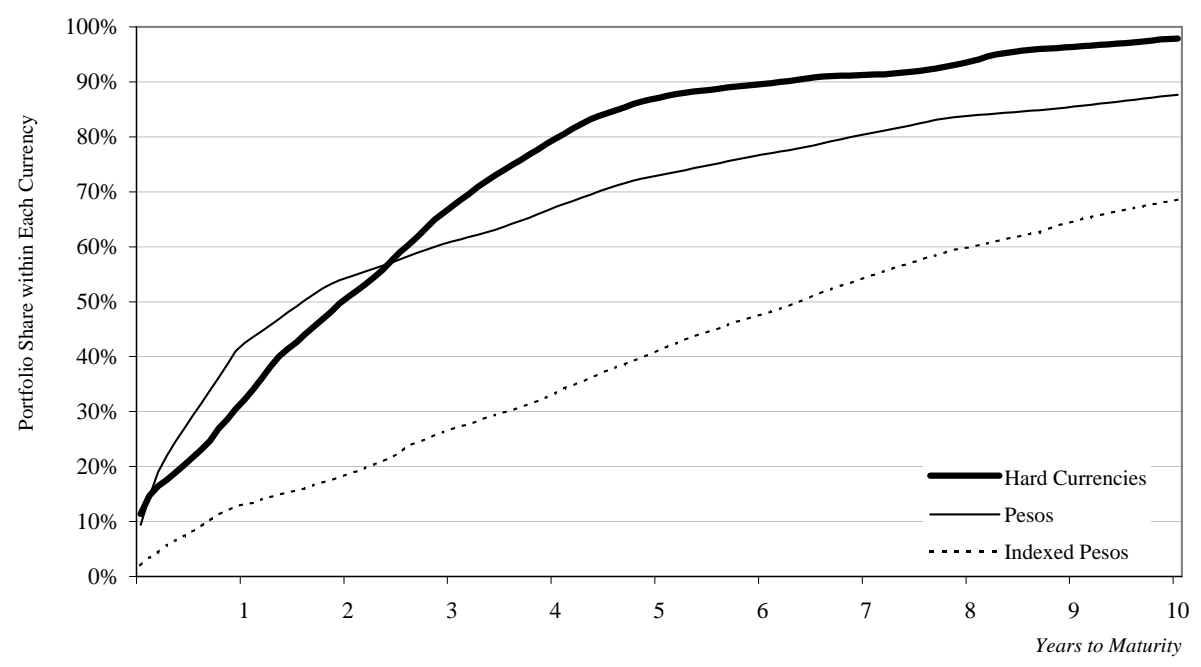

B. Chilean PFAs by Currency

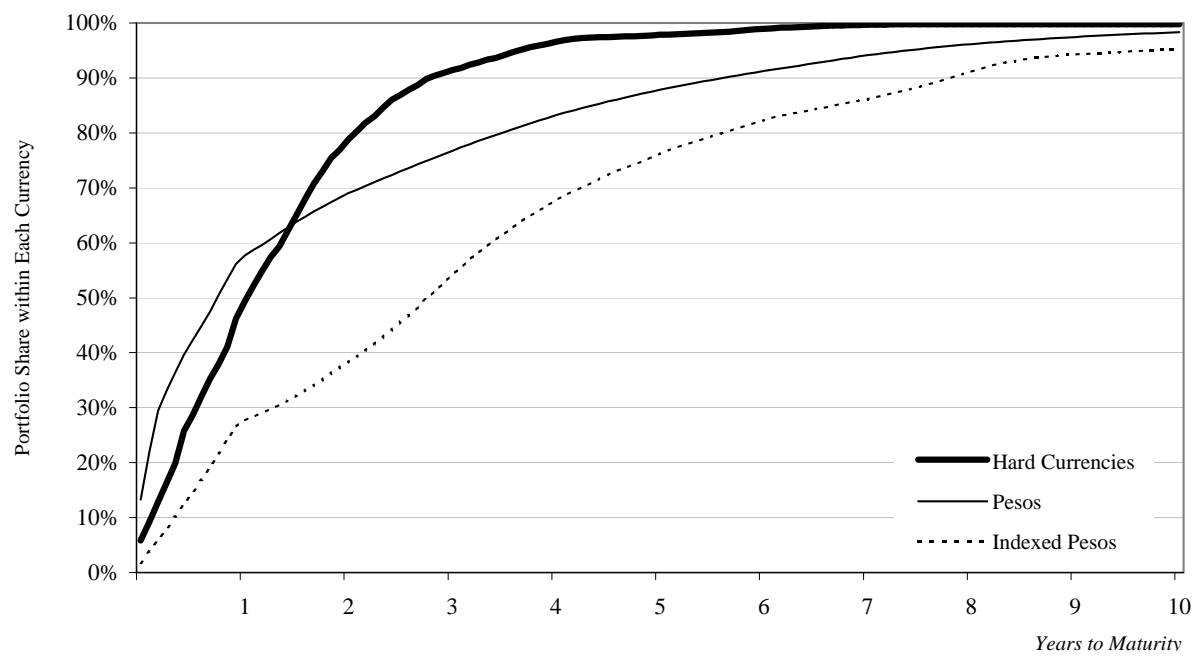

C. Overall Portfolio Weights by Currency

\begin{tabular}{|c|c|c|c|c|c|}
\hline & & & $\begin{array}{c}(1) \\
\text { Pesos }\end{array}$ & $\begin{array}{c}(2) \\
\text { Indexed Pesos }\end{array}$ & $\begin{array}{c}\text { (3) } \\
\text { Hard Currencies }\end{array}$ \\
\hline$\overline{\text { Chilean I }}$ & utual Funds & & $81 \%$ & $6 \%$ & $13 \%$ \\
\hline Chilean F & & & $22 \%$ & $73 \%$ & $5 \%$ \\
\hline \multicolumn{6}{|c|}{ D. Average Years to Maturity } \\
\hline & & & (1) & (2) & (3) \\
\hline & & & Pesos & Indexed Pesos & Hard Currencies \\
\hline Chilean I & utual Funds & & 3.59 & 6.71 & 3.37 \\
\hline Chilean F & & & 2.08 & 3.61 & 1.60 \\
\hline \multicolumn{6}{|c|}{ E. Hypothesis Testing } \\
\hline & (i) & (ii) & & (iii) & (iv) \\
\hline \multicolumn{3}{|c|}{ Chilean Mutual Funds } & & \multicolumn{2}{|c|}{ Chilean PFAs } \\
\hline & t-test & KS & & t-test & KS \\
\hline$(1)=(2)$ & $<0.01^{* * *}$ & $<0.01^{* * *}$ & $(1)=(2)$ & $<0.01^{* * *}$ & $<0.01 * * *$ \\
\hline$(1)=(3)$ & 0.64 & $<0.01 * * *$ & $(1)=(3)$ & $0.01 * * *$ & $0.01 * *$ \\
\hline$(2)=(3)$ & $<0.01^{* * *}$ & $<0.01 * * *$ & $(2)=(3)$ & $0.03 * *$ & $0.01^{* * *}$ \\
\hline
\end{tabular}


Figure 9

\section{Maturity Structure of Chilean Mutual Funds and PFAs by Currency Compared to US Mutual Funds}

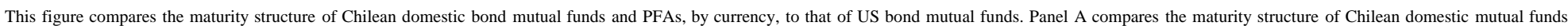

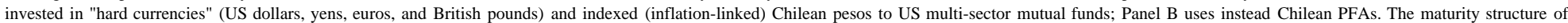

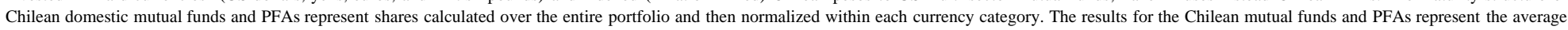

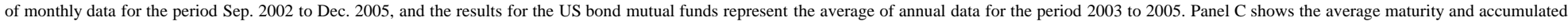

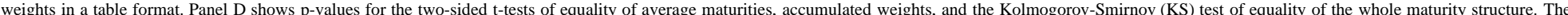

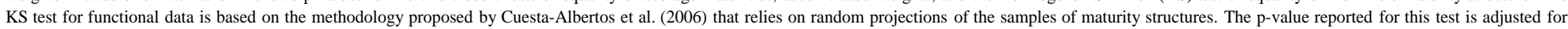

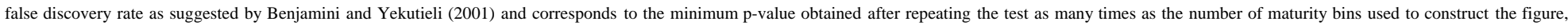
using a different random projection vector in each repetition. *, ${ }^{* *}$, and ${ }^{* * *}$ represent statistical significance at the $10 \%, 5 \%$, and $1 \%$ level, respectively.
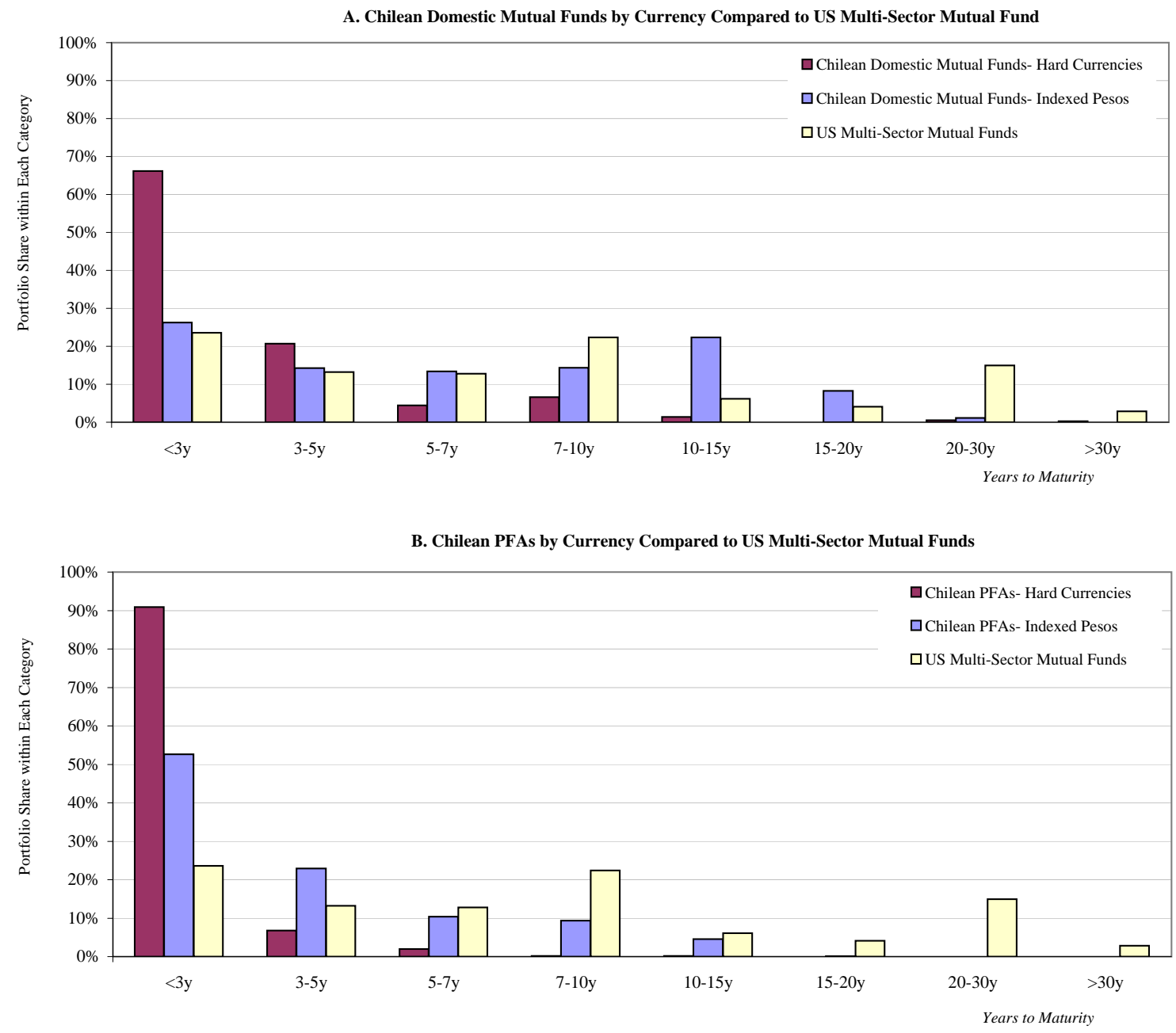

C. Average Maturity and Accumulated Weights

\begin{tabular}{|c|c|c|c|c|c|c|c|c|}
\hline & (i) & (ii) & (iii) & (iv) & (v) & (vi) & (vii) & (viii) \\
\hline & & \multicolumn{7}{|c|}{ Accumulated Weights } \\
\hline & Avg. Maturity & $<3$ years $(\mathrm{y})$ & $<5 y$ & $<7 y$ & $<10 \mathrm{y}$ & $<15 y$ & $<20 \mathrm{y}$ & $<30 y$ \\
\hline (1) Chilean Domestic Mutual Funds - Hard Currencies & 3.37 & $66 \%$ & $87 \%$ & $91 \%$ & $98 \%$ & $99 \%$ & $99 \%$ & $100 \%$ \\
\hline (2) Chilean Domestic Mutual Funds - Indexed Pesos & 6.71 & $26 \%$ & $41 \%$ & $54 \%$ & $68 \%$ & $91 \%$ & $99 \%$ & $100 \%$ \\
\hline (3) Chilean PFAs - Hard Currencies & 1.60 & $91 \%$ & $98 \%$ & $100 \%$ & $100 \%$ & $100 \%$ & $100 \%$ & $100 \%$ \\
\hline (4) Chilean PFAs - Indexed Pesos & 3.61 & $53 \%$ & $76 \%$ & $86 \%$ & $95 \%$ & $100 \%$ & $100 \%$ & $100 \%$ \\
\hline (5) US Multi-Sector Mutual Funds & 9.55 & $24 \%$ & $37 \%$ & $50 \%$ & $72 \%$ & $78 \%$ & $82 \%$ & $97 \%$ \\
\hline \multicolumn{9}{|l|}{ D. Hypothesis Testing } \\
\hline & \multirow[t]{2}{*}{ (i) } & (ii) & (iii) & (iv) & (v) & (vi) & (vii) & (viii) \\
\hline & & \multicolumn{6}{|c|}{ Accumulated Weights } & \\
\hline & Avg. Maturity & $<3$ years $(\mathrm{y})$ & $<5 y$ & $<7 y$ & $<10 \mathrm{y}$ & $<15 y$ & $>20 \mathrm{y}$ & KS \\
\hline$(1)=(5)$ & $<0.01^{* * *}$ & $<0.01 * * *$ & $<0.01^{* * *}$ & $<0.01 * * *$ & $<0.01^{* * *}$ & $<0.01 * * *$ & $<0.01^{* * *}$ & $<0.01^{* * *}$ \\
\hline$(2)=(5)$ & $<0.01 * * *$ & $0.08 *$ & $0.03 * *$ & $0.02 * *$ & 0.56 & $<0.01 * * *$ & $<0.01^{* * *}$ & $<0.01^{* * *}$ \\
\hline$(3)=(5)$ & $<0.01 * * *$ & $<0.01 * * *$ & $<0.01 * * *$ & $<0.01^{* * *}$ & $<0.01^{* * *}$ & $<0.01^{* * *}$ & $<0.01^{* * *}$ & $<0.01 * * *$ \\
\hline$(4)=(5)$ & $<0.01 * * *$ & $<0.01 * * *$ & $<0.01 * * *$ & $<0.01 * * *$ & $<0.01 * * *$ & $<0.01 * * *$ & $<0.01 * * *$ & $<0.01 * * *$ \\
\hline
\end{tabular}




\section{Figure 10 \\ Maturity Structure of Chilean and US Mutual Funds Controlling for Assets}

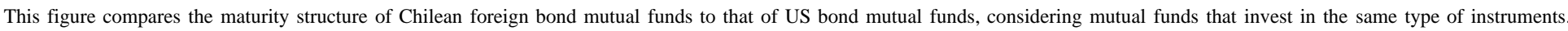

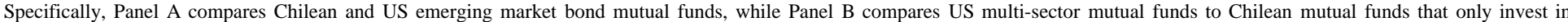

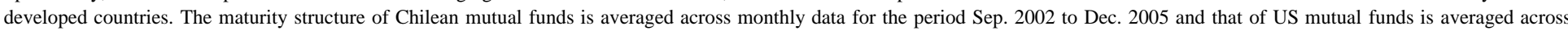

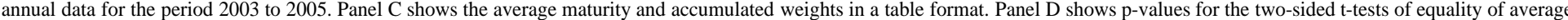

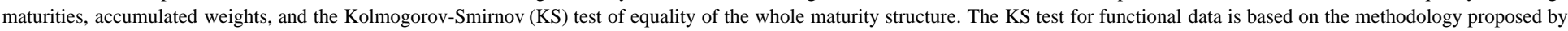

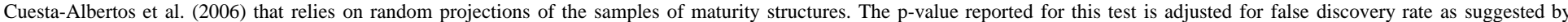

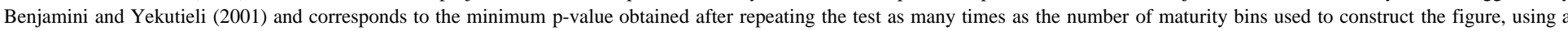

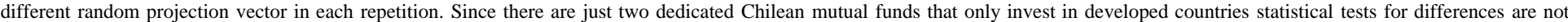
reported. *,**, and $* * *$ represent statistical significance at the $10 \%, 5 \%$, and $1 \%$ level, respectively.

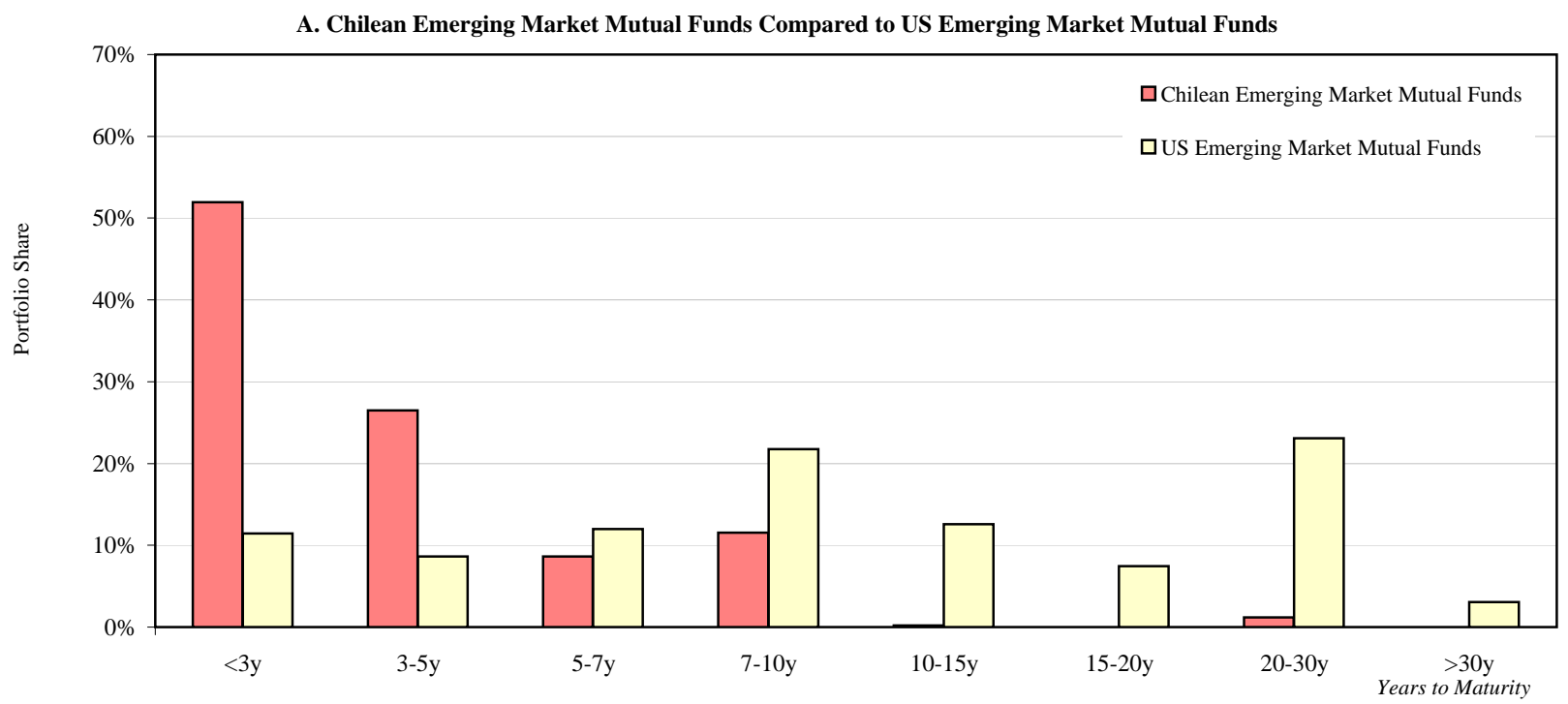

B. Chilean Developed Country Mutual Funds Compared to US Multi-Sector Mutual Funds

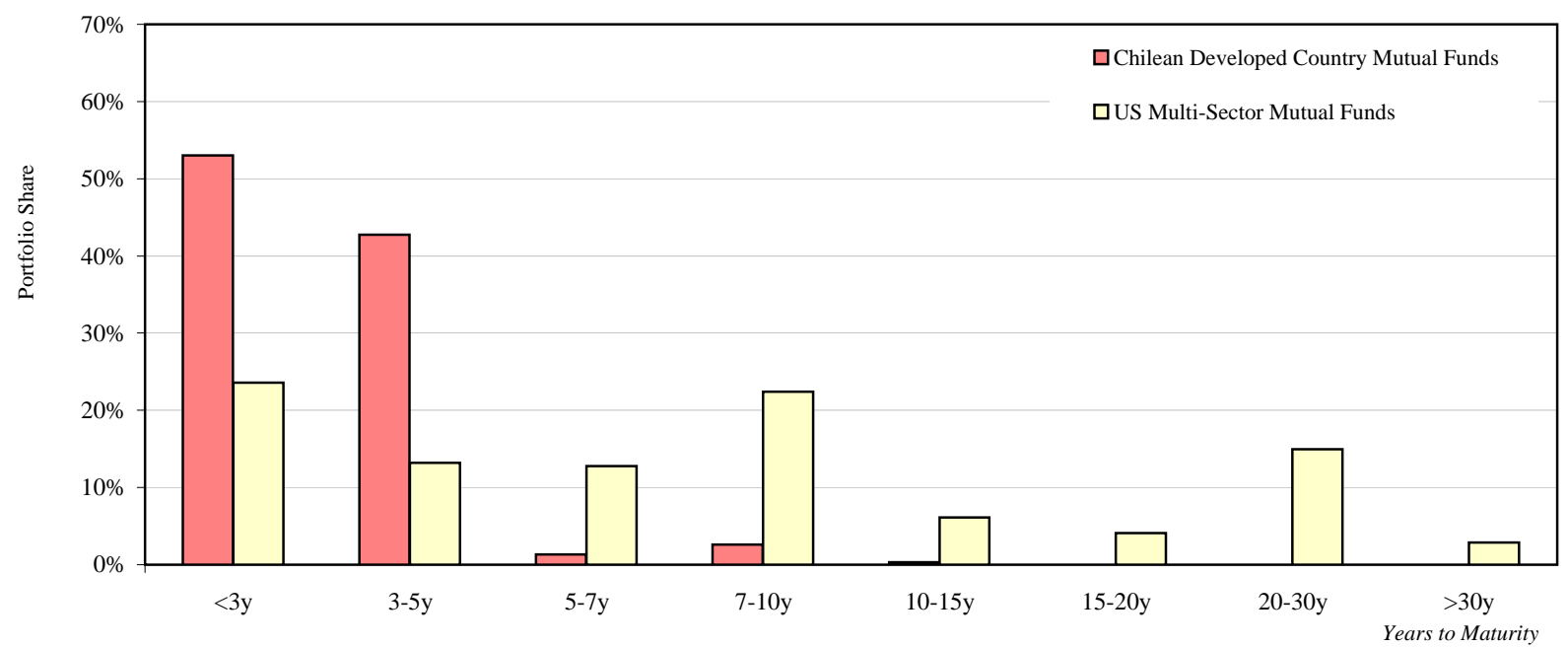

C. Average Maturity and Accumulated Weights

\begin{tabular}{|c|c|c|c|c|c|c|c|c|}
\hline & (i) & (ii) & (iii) & (iv) & (v) & (vi) & (vii) & (viii) \\
\hline & \multicolumn{8}{|c|}{ Accumulated Weights } \\
\hline & Avg. Maturity & $<$ 3years (y) & $<5 y$ & $<7 \mathrm{y}$ & $<10 y$ & $<15 y$ & $<20 y$ & $<30 y$ \\
\hline (1) Chilean Emerging Market Mutual Funds & 3.80 & $52 \%$ & $78 \%$ & $87 \%$ & $99 \%$ & $99 \%$ & $99 \%$ & $100 \%$ \\
\hline (2) US Emerging Market Mutual Funds & 12.64 & $11 \%$ & $20 \%$ & $32 \%$ & $54 \%$ & $66 \%$ & $74 \%$ & $97 \%$ \\
\hline (3) Chilean Developed Country Mutual Funds & 3.77 & $53 \%$ & $96 \%$ & $97 \%$ & $100 \%$ & $100 \%$ & $100 \%$ & $100 \%$ \\
\hline (4) US Multi-Sector Mutual Funds & 9.55 & $24 \%$ & $37 \%$ & $50 \%$ & $72 \%$ & $78 \%$ & $82 \%$ & $97 \%$ \\
\hline \multicolumn{9}{|l|}{ D. Hypothesis Testing } \\
\hline & (i) & (ii) & (iii) & (iv) & (v) & (vi) & (vii) & (viii) \\
\hline & & \multicolumn{7}{|c|}{ Accumulated Weights } \\
\hline & Avg. Maturity & $<$ 3years (y) & $<5 y$ & $<7 y$ & $<10 \mathrm{y}$ & $<15 y$ & $>20 y$ & KS \\
\hline$(1)=(2)$ & $<0.01 * * *$ & $<0.01^{* * *}$ & $<0.01^{* * *}$ & $<0.01 * * *$ & $<0.01^{* * *}$ & $<0.01^{* * *}$ & $<0.01^{* * *}$ & $<0.01 * * *$ \\
\hline
\end{tabular}




\section{Figure 11}

\section{Net Inflows to Chilean Mutual Funds and PFAs Compared to US Mutual Funds}

This figure presents the cumulative distribution of net monthly inflows of funds to Chilean domestic bond mutual funds, Chilean PFAs, and US bond mutual funds as a fraction of their fixed-term assets. Net inflows to Chilean and US mutual funds (Chilean PFAs) are computed for each mutual fund (PFA) as the difference between the contemporaneous and lagged value of a mutual fund's (PFA's) assets and the returns accrued from the assets in the previous month's portfolio, and are divided by the contemporaneous value of a mutual fund's (PFA's) fixed-term assets. The sample period is Sep. 2002 to Dec. 2005. Panel A shows the empirical cumulative probability distributions of these normalized inflows across mutual funds (PFAs) and months, under the assumption that normalized inflows are independent and identically distributed across mutual funds (PFAs) and time. The distribution of US and Chilean mutual fund inflows are shown only partially because they have been limited to fit the scale of the distribution of PFA inflows. Panel B reports the fraction of the fixed-term portfolio invested by the average mutual fund (PFA) up to one and three months (reported in the first and third columns) and the probabilities of observing an outflow larger than that magnitude (reported in the second and fourth columns). These probabilites are obtained from the empirical distributions shown in Panel A. Estimations for the US for Panel B are based on the assumption that within the zero to three year interval, the maturity structure of US funds is the same as that of Chilean mutual funds.

\section{A. Cumulative Distribution of Net Inflows}

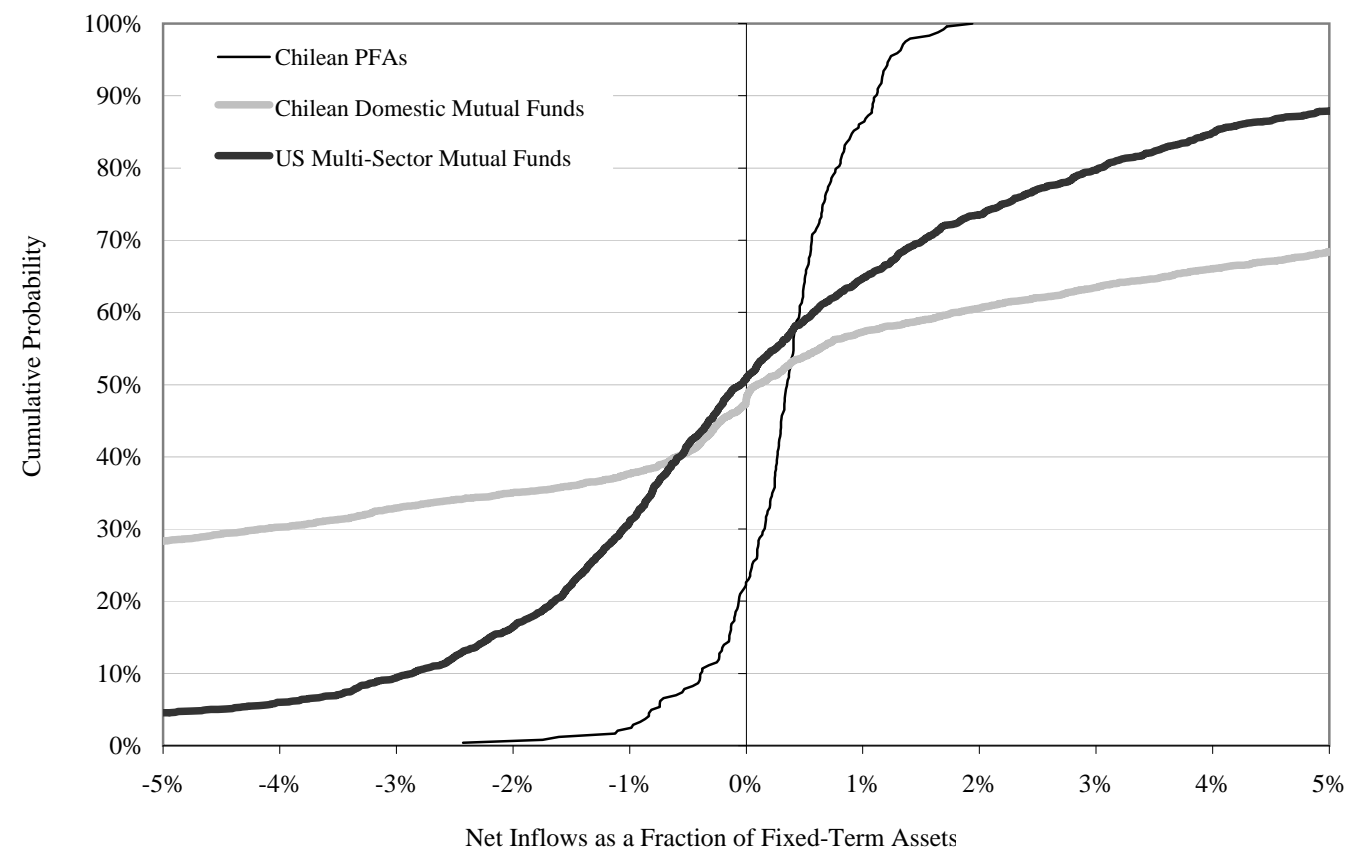

B. Percentage of Assets Held Short Term and Probability of Outflows of that Magnitude

\begin{tabular}{|c|c|c|c|c|}
\hline & \multicolumn{2}{|r|}{ Probability } & \multirow[b]{2}{*}{$\begin{array}{c}\% \text { of } \\
\text { Short-Term } \\
\text { Assets }\end{array}$} & \multirow[b]{2}{*}{$\begin{array}{c}\text { Probability } \\
\text { Outflows }> \\
\% \text { of } \\
\text { Short-Term } \\
\text { Assets }\end{array}$} \\
\hline & $\begin{array}{c}\% \text { of } \\
\text { Short-Term } \\
\text { Assets }\end{array}$ & $\begin{array}{c}\text { Outflows > } \\
\% \text { of } \\
\text { Short-Term } \\
\text { Assets } \\
\end{array}$ & & \\
\hline & \multicolumn{2}{|c|}{ Up to 1 month } & \multicolumn{2}{|c|}{ Up to 3 months } \\
\hline Chilean Domestic Mutual Funds & $9.3 \%$ & $21.6 \%$ & $17.9 \%$ & $13.4 \%$ \\
\hline Chilean PFAs & $4.4 \%$ & $0.0 \%$ & $11.2 \%$ & $0.0 \%$ \\
\hline US Multisector Bond Funds & $3.7 \%$ & $6.6 \%$ & $7.1 \%$ & $2.8 \%$ \\
\hline
\end{tabular}




\section{Figure 12 \\ Maturity Structure of Chilean Mutual Funds Domestic Funds Compared to Emerging Market Funds}

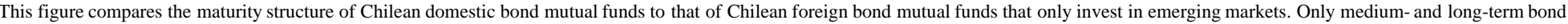

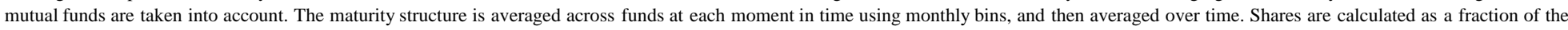

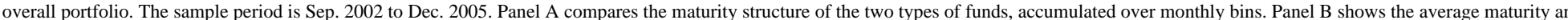

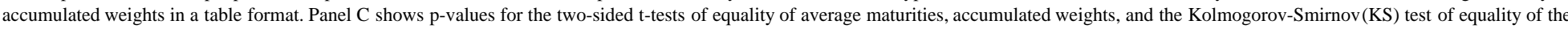

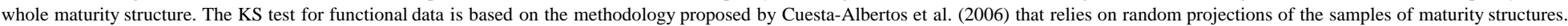

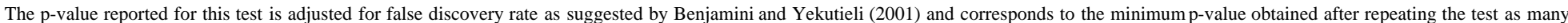

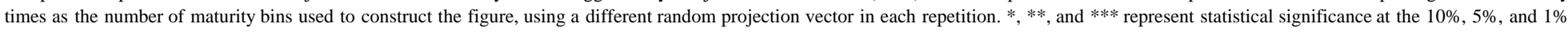
level, respectively.

\section{A. Accumulated Weights}

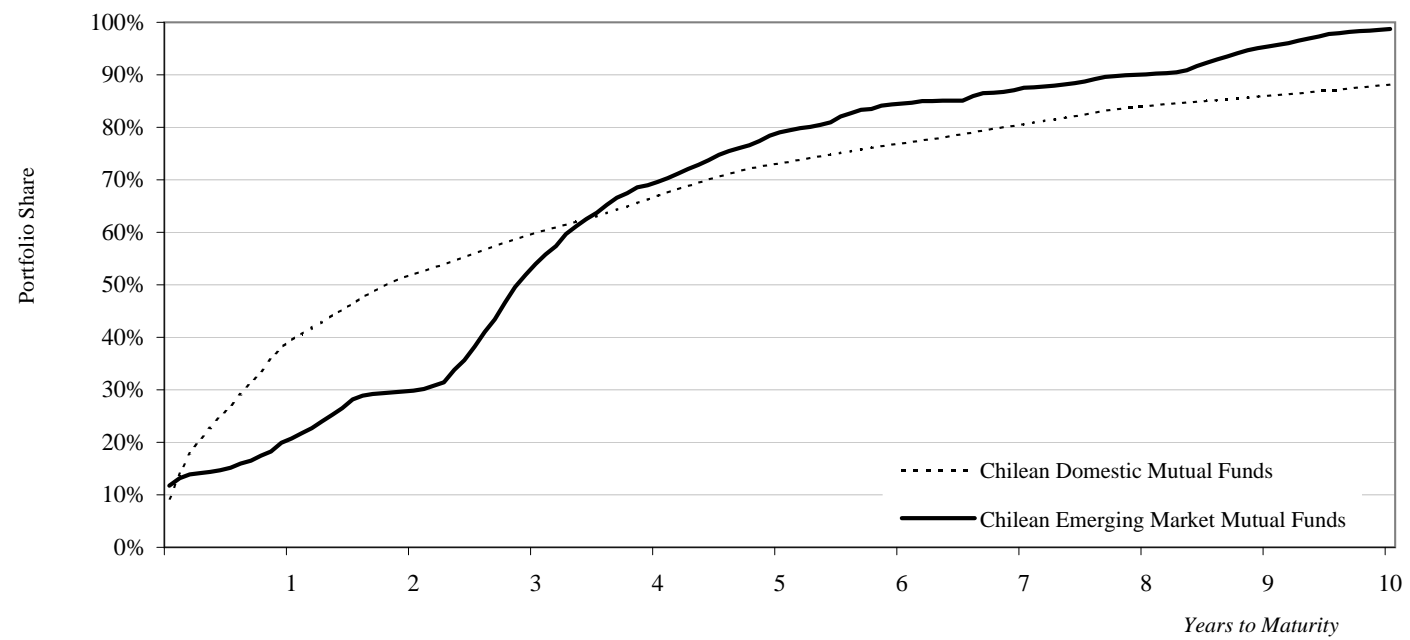

\section{B. Average Maturity and Accumulated Weights}

\begin{tabular}{|c|c|c|c|c|c|c|c|c|c|}
\hline & (i) & (ii) & (iii) & (iv) & (v) & (vi) & (vii) & (viii) & (ix) \\
\hline & & \multicolumn{8}{|c|}{ Accumulated Weights } \\
\hline & Avg. Maturity & $<$ 1year (y) & $<3 y$ & $<5 y$ & $<7 y$ & $<10 \mathrm{y}$ & $<15 y$ & $<20 \mathrm{y}$ & $<30 \mathrm{y}$ \\
\hline (1) Chilean Domestic Mutual Funds & 3.88 & $38 \%$ & $59 \%$ & $73 \%$ & $80 \%$ & $88 \%$ & $95 \%$ & $99 \%$ & $100 \%$ \\
\hline (2) Chilean Emerging Market Mutual Funds & 3.80 & $20 \%$ & $52 \%$ & $78 \%$ & $87 \%$ & $99 \%$ & $99 \%$ & $99 \%$ & $100 \%$ \\
\hline \multicolumn{10}{|l|}{ C. Hypothesis Testing } \\
\hline & (i) & (ii) & (iii) & (iv) & (v) & (vi) & (vii) & (viii) & (ix) \\
\hline & & \multicolumn{8}{|c|}{ Accumulated Weights } \\
\hline & Avg. Maturity & $<$ 1year (y) & $<3 y$ & $<5 y$ & $<7 y$ & $<10 \mathrm{y}$ & $<15 y$ & $>20 y$ & KS \\
\hline$(1)=(2)$ & 0.85 & $<0.01^{* * *}$ & 0.31 & 0.92 & 0.55 & $0.03 * *$ & 0.14 & 0.31 & $0.09^{*}$ \\
\hline
\end{tabular}


Figure 13

\section{Maturity Structure of Chilean Insurance Companies Compared to Mutual Funds and PFAs}

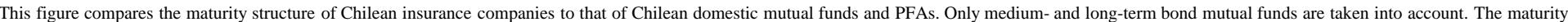

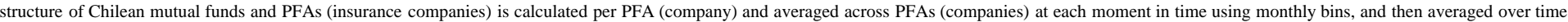

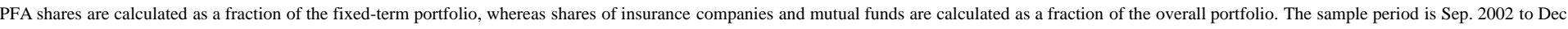

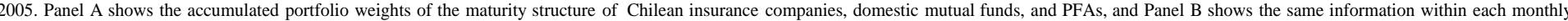

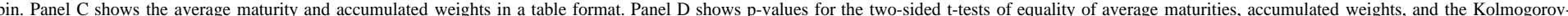

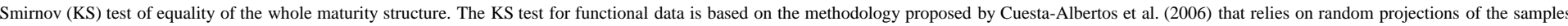

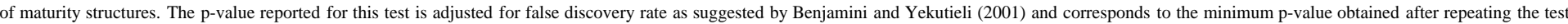

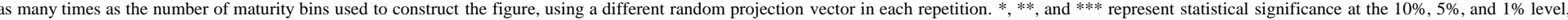
respectively.

A. Accumulated Weights

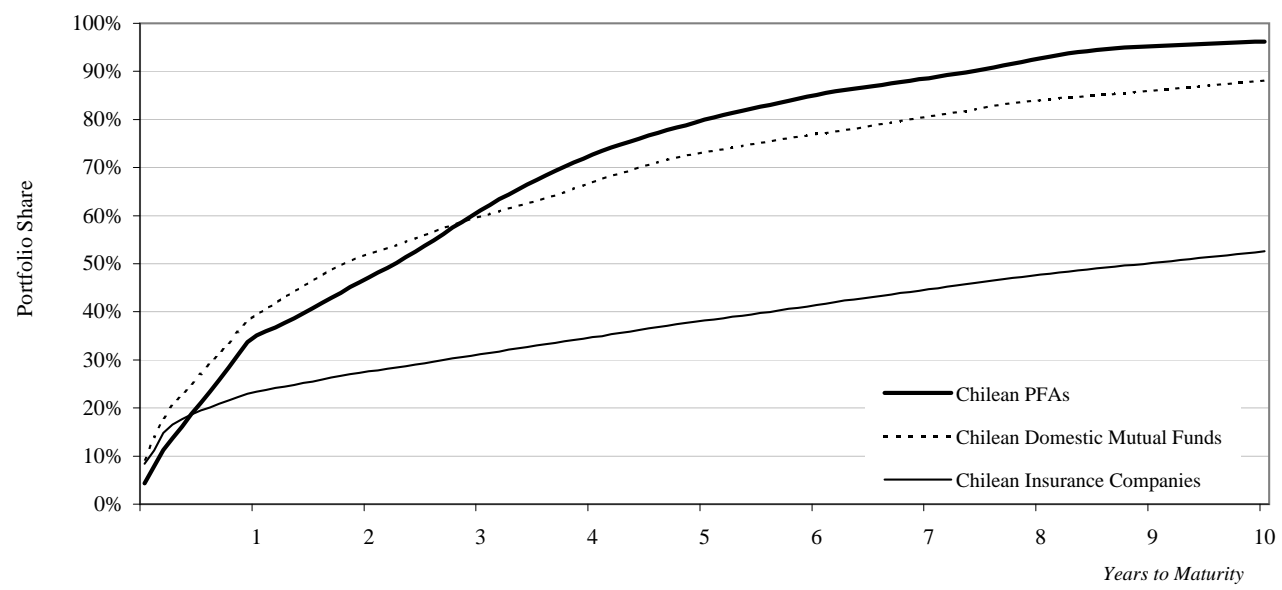

B. Weights within Each Maturity Range

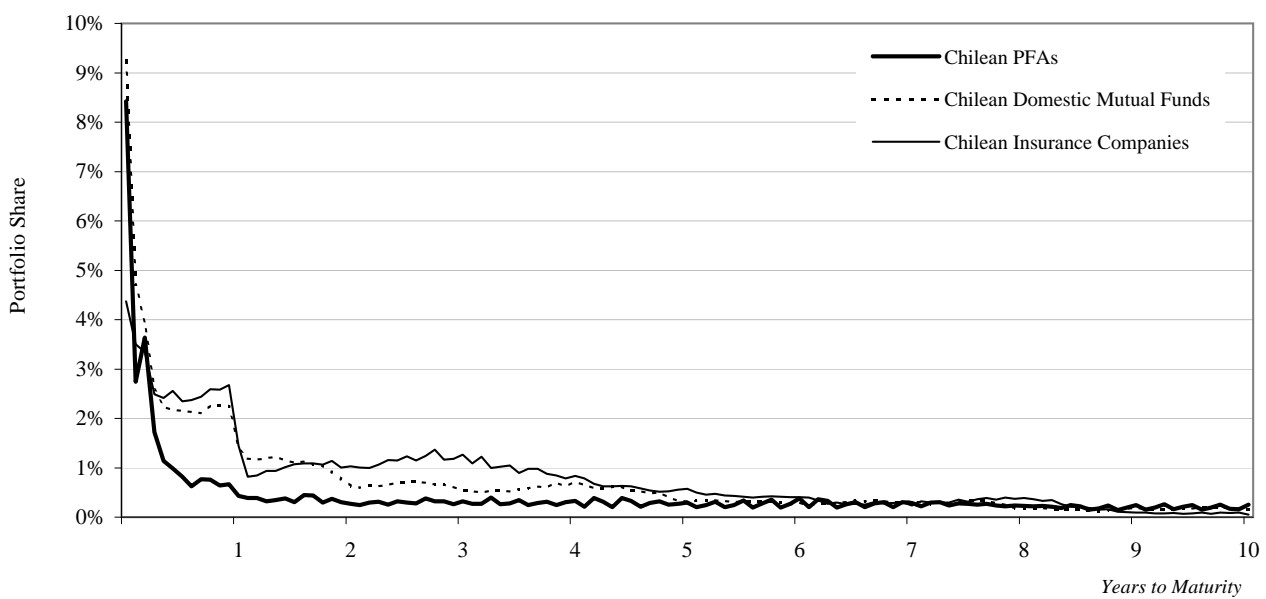

C. Average Maturity and Accumulated Weights

\begin{tabular}{|c|c|c|c|c|c|c|c|c|c|}
\hline & (i) & (ii) & (iii) & (iv) & (v) & (vi) & (vii) & (viii) & (ix) \\
\hline & & \multicolumn{8}{|c|}{ Accumulated Weights } \\
\hline & Avg. Maturity & $<1$ year $(y)$ & $<3 y$ & $<5 y$ & $<7 \mathrm{y}$ & $<10 \mathrm{y}$ & $<15 y$ & $<20 \mathrm{y}$ & $<30 \mathrm{y}$ \\
\hline (1) Chilean Insurance Companies & 10.32 & $23 \%$ & $31 \%$ & $38 \%$ & $44 \%$ & $52 \%$ & $66 \%$ & $86 \%$ & $100 \%$ \\
\hline (2) Chilean Domestic Mutual Funds & 3.88 & $38 \%$ & $59 \%$ & $73 \%$ & $80 \%$ & $88 \%$ & $95 \%$ & $99 \%$ & $100 \%$ \\
\hline (3) Chilean PFAs & 3.16 & $34 \%$ & $60 \%$ & $79 \%$ & $88 \%$ & $96 \%$ & $100 \%$ & $100 \%$ & $100 \%$ \\
\hline \multicolumn{10}{|l|}{ D. Hypothesis Testing } \\
\hline & (i) & (ii) & (iii) & (iv) & (v) & (vi) & (vii) & (viii) & (ix) \\
\hline & & \multicolumn{8}{|c|}{ Accumulated Weights } \\
\hline & Avg. Maturity & $<1$ year (y) & $<3 y$ & $<5 y$ & $<7 y$ & $<10 \mathrm{y}$ & $<15 y$ & $>20 \mathrm{y}$ & KS \\
\hline$(1)=(2)$ & $<0.01^{* * *}$ & $<0.01 * * *$ & $<0.01^{* * *}$ & $<0.01^{* * *}$ & $<0.01^{* * *}$ & $<0.01^{* * *}$ & $<0.01^{* * *}$ & $<0.01^{* * *}$ & $<0.01^{* * *}$ \\
\hline$(1)=(3)$ & $<0.01 * * *$ & 0.40 & $0.02 * *$ & $<0.01 * * *$ & $<0.01^{* * *}$ & $<0.01 * * *$ & $<0.01^{* * *}$ & $<0.01 * * *$ & $<0.01^{* * *}$ \\
\hline
\end{tabular}


Table 1

\section{PFA Holdings of Outstanding Corporate Debt}

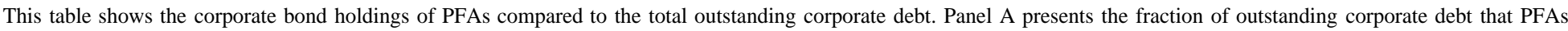

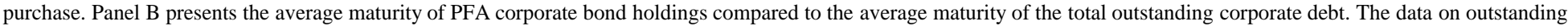

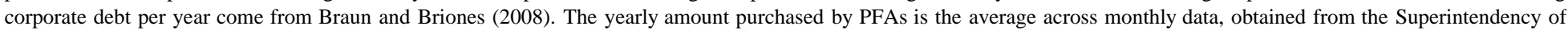

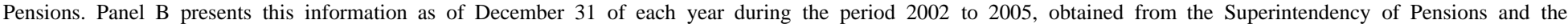
Superintendency of Securities and Insurance of Chile.

\section{A. Fraction of Outstanding Corporate Debt Held by PFAs}

\begin{tabular}{cccc}
\hline Year & $\begin{array}{c}\text { Outstanding Corporate Debt } \\
\text { (Millions of US Dollars) }\end{array}$ & $\begin{array}{c}\text { Purchased by PFAs } \\
\text { (Millions of US Dollars) }\end{array}$ & $\begin{array}{c}\text { Purchased by PFAs } \\
\text { (Percentage of Outstanding } \\
\text { Corporate Debt) }\end{array}$ \\
\hline 1997 & $\$ 2,047$ & $\$ 1,195$ & $58 \%$ \\
1998 & $\$ 1,699$ & $\$ 941$ & $55 \%$ \\
1999 & $\$ 2,156$ & $\$ 1,214$ & $56 \%$ \\
2000 & $\$ 3,974$ & $\$ 1,388$ & $35 \%$ \\
2001 & $\$ 6,076$ & $\$ 1,723$ & $28 \%$ \\
2002 & $\$ 8,293$ & $\$ 2,331$ & $28 \%$ \\
2003 & $\$ 9,790$ & $\$ 2,901$ & $30 \%$ \\
2004 & $\$ 12,931$ & $\$ 3,650$ & $28 \%$ \\
\hline
\end{tabular}

B. Average Maturity (in Years) of PFA Corporate Bond Holdings vs. Total Outstanding Corporate Debt

\begin{tabular}{lcccc}
\hline & Dec. 2002 & Dec. 2003 & Dec. 2004 & Dec. 2005 \\
\hline PFA Holdings of Corporate Debt & 4.9 & 5 & 5.8 & 6.1 \\
Outstanding Corporate Debt & 12.2 & 12.7 & 14 & 14.7 \\
\hline
\end{tabular}




\section{Appendix Table 1 Description of Main Data}

This table presents information on the main data used in this paper by type of institutional investor. It includes the sample period, data frequency, number of observations, number of funds, and data source. Number of funds refers to the number of mutual funds, the number of insurance companies, or number of pension funds in each case. The pension fund data are aggregated and used at the pension fund administrator (PFA) level throughout the paper.

\begin{tabular}{lccrcc}
\hline Institutional Investor & Sample Period & Frequency & $\begin{array}{c}\text { No. of } \\
\text { Observations }\end{array}$ & \multicolumn{1}{c}{$\begin{array}{c}\text { No. of } \\
\text { Funds / } \\
\text { Companies }\end{array}$} \\
\hline Chilean Domestic Mutual Funds & Sep. 2002 to Dec. 2005 & Monthly & 436,393 & 67 & Superintendency of Securities and Insurance of Chile \\
Chilean Foreign Mutual Funds & Sep. 2002 to Dec. 2005 & Monthly & 11,271 & 11 & Superintendency of Securities and Insurance of Chile \\
Chilean Insurance Companies & Jun. 2002 to Dec. 2005 & Monthly & $2,156,576$ & 36 & Superintendency of Securities and Insurance of Chile \\
Chilean Pension Funds & Jul. 1996 to Dec. 2005 & Monthly & $7,501,210$ & 57 & Superintendency of Pensions of Chile \\
Chilean Pension Funds & Jul. 1996 to Jul. 2008 & Daily & $201,288,833$ & 62 & Superintendency of Pensions of Chile \\
US Mutual Funds & 2003 - 2005 & Annually & 11,440 & 186 & Morningstar \\
\hline
\end{tabular}

